\title{
Caffeic Acid/Eu(III) Complexes: Solution Equilibrium Studies, Structure Characterization and Biological Activity
}

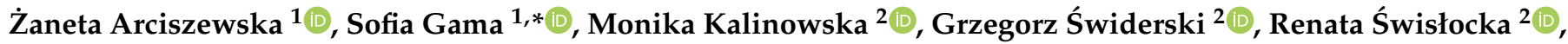

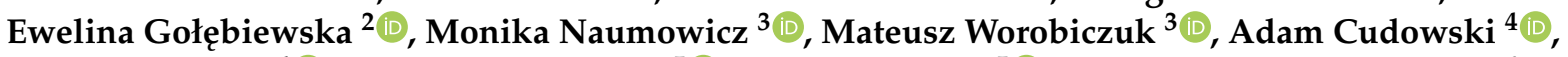

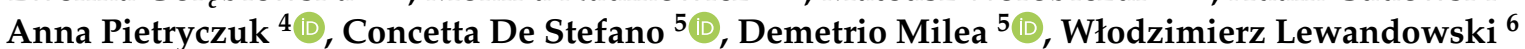 \\ and Beata Godlewska-Żyłkiewicz ${ }^{1, *}$ (1)
}

Citation: Arciszewska, Ż.; Gama, S.; Kalinowska, M.; Świderski, G.;

Świsłocka, R.; Gołębiewska, E.;

Naumowicz, M.; Worobiczuk, M.; Cudowski, A.; Pietryczuk, A.; et al. Caffeic Acid/Eu(III) Complexes: Solution Equilibrium Studies, Structure Characterization and Biological Activity. Int. J. Mol. Sci. 2022, 23, 888. https://doi.org/ $10.3390 /$ ijms 23020888

Academic Editor: Davide Barreca

Received: 10 December 2021

Accepted: 11 January 2022

Published: 14 January 2022

Publisher's Note: MDPI stays neutral with regard to jurisdictional claims in published maps and institutional affiliations.

Copyright: (C) 2022 by the authors. Licensee MDPI, Basel, Switzerland. This article is an open access article distributed under the terms and conditions of the Creative Commons Attribution (CC BY) license (https:// creativecommons.org/licenses/by/ $4.0 /)$.
1 Department of Analytical and Inorganic Chemistry, Faculty of Chemistry, University of Bialystok, K. Ciołkowskiego 1K, 15-245 Białystok, Poland; z.arciszewska@uwb.edu.pl

2 Department of Chemistry, Biology and Biotechnology, Bialystok University of Technology, Wiejska 45E, 15-351 Białystok, Poland; m.kalinowska@pb.edu.pl (M.K.); g.swiderski@pb.edu.pl (G.Ś.); r.swislocka@pb.edu.pl (R.Ś.); e.golebiewska@pb.edu.pl (E.G.)

3 Department of Physical Chemistry, Faculty of Chemistry, University of Bialystok, K. Ciołkowskiego 1K, 15-245 Białystok, Poland; monikan@uwb.edu.pl (M.N.); mworobiczuk@gmail.com (M.W.)

4 Department of Water Ecology, Faculty of Biology, University of Bialystok, K. Ciołkowskiego 1J, 15-245 Białystok, Poland; cudad@uwb.edu.pl (A.C.); annapiet@uwb.edu.pl (A.P.)

5 Dipartimento di Scienze Chimiche, Biologiche, Farmaceutiche ed Ambientali, CHIBIOFARAM, Università degli Studi di Messina, V.le F. Stagno d'Alcontres, 31, 98166 Messina, Italy; cdestefano@unime.it (C.D.S.); dmilea@unime.it (D.M.)

6 Prof Waclaw Dabrowski Institute of Agricultural and Food Biotechnology—State Research Institute, 36 Rakowiecka St., 02-532 Warsaw, Poland; w.lewandowski@pb.edu.pl

* Correspondence: sofia.gama@uwb.edu.pl (S.G.); bgodlew@uwb.edu.pl (B.G.-Ż.); Tel.: +48-8573-88090 (S.G.); +48-8573-88257 (B.G.-Ż.)

Abstract: Caffeic acid (CFA) is one of the various natural antioxidants and chemoprotective agents occurring in the human diet. In addition, its metal complexes play fundamental roles in biological systems. Nevertheless, research on the properties of CFA with lanthanide metals is very scarce, and little to no chemical or biological information is known about these particular systems. Most of their properties, including their biological activity and environmental impact, strictly depend on their structure, stability, and solution behaviour. In this work, a multi-analytical-technique approach was used to study these relationships for the Eu(III)/CFA complex. The synthesized metal complex was studied by FT-IR, FT-Raman, elemental, and thermal (TGA) analysis. In order to examine the chemical speciation of the $\mathrm{Eu}(\mathrm{III}) / \mathrm{CFA}$ system in an aqueous solution, several independent potentiometric and spectrophotometric UV-Vis titrations were performed at different M:L (metal:ligand) and $\mathrm{pH}$ ratios. The general molecular formula of the synthesized metal complex in the solid state was $\left[\mathrm{Eu}(\mathrm{CFA})_{3}\left(\mathrm{H}_{2} \mathrm{O}\right)_{3}\right] \cdot 2 \mathrm{H}_{2} \mathrm{O}$ (M:L ratio 1:3), while in aqueous solution the 1:1 species were observed at the optimum $\mathrm{pH}$ of $6 \leq \mathrm{pH} \leq 10,\left([\mathrm{Eu}(\mathrm{CFA})]\right.$ and $\left.[\mathrm{Eu}(\mathrm{CFA})(\mathrm{OH})]^{-}\right)$. These results were confirmed by ${ }^{1} \mathrm{H}-\mathrm{NMR}$ experiments and electrospray-ionization mass spectrometry (ESI-MS). To evaluate the interaction of $\mathrm{Eu}(\mathrm{III}) / \mathrm{CFA}$ and CFA alone with cell membranes, electrophoretic mobility assays were used. Various antioxidant tests have shown that $\mathrm{Eu}(\mathrm{III}) / \mathrm{CFA}$ exhibits lower antioxidant activity than the free CFA ligand. In addition, the antimicrobial properties of Eu(III)/CFA and CFA against Escherichia coli, Bacillus subtilis and Candida albicans were investigated by evaluation of the minimum inhibitory concentration (MIC). Eu(III)/CFA shows higher antibacterial activity against bacteria compared to CFA, which can be explained by the highly probable increased lipophilicity of the Eu(III) complex.

Keywords: antimicrobial activity; antioxidant activity; chemical speciation; lanthanides; metal complexes; microelectrophoretic mobility; polyphenols; sequestering ability; solution equilibria 


\section{Introduction}

Natural carboxylic acids occur widely in nature. Among them, polyphenols are considered to be the most important agents responsible for many biological functions. Plant phenolics include simple phenols, phenolic acids, flavonoids, coumarins, stilbenes, hydrolysable and condensed tannins, lignans, and lignins. They can be found in the edible parts of many plants such as fruits, seeds, leaves, stems, and roots. Their occurrence, distribution in plants, structure, biochemical activity and other unique properties have been extensively studied in the field of bioinorganic, food and pharmaceutical chemistry, due to their various biological and pharmacological activities, including antioxidant, antimicrobial and anticancer activities [1].

Polyphenolic acids can be divided into two major groups: hydroxybenzoic and hydroxycinnamic acids. All compounds contain one or more hydroxyl groups attached directly to the aromatic ring. The caffeic acid (3-(3,4-Dihydroxyphenyl)-2-propenoic acid, Scheme 1a), from now on designated as CFA (in its fully deprotonated form of caffeinate it will be denoted as $\mathrm{L}^{3-}$, Scheme $1 \mathrm{~b}$ ), is one of the most abundant hydroxycinnamic acids, with a very well demonstrated antibacterial activity, and is described in numerous publications [1-7]. The observed biological activity seems to result from the ability of CFA to damage the cell membrane integrity and/or change its permeability, to inhibit some particular enzymatic activity, to trigger protein damage, or to change DNA structure [7].<smiles>O=C(O)/C=C/c1ccc(O)c(O)c1</smiles>

(a)<smiles>[O-][O+]=C([O-])/C=C/c1ccc([O-])c([O-])c1</smiles>

(b)

Scheme 1. Chemical structure of CFA in its fully protonated $\left(\mathrm{CFA}, \mathrm{LH}_{3}\right)$ and deprotonated $\left(\mathrm{L}^{3-}\right)$ forms: (a) caffeic acid (CFA, $\left.\mathrm{LH}_{3}\right)$; (b) caffeinate $\left(\mathrm{L}^{3-}\right)$.

In spite of the important role of this molecule in the environmental and biological fields, including human nutrition, very little is known about the structure and properties of CFA complexes with metal ions, especially with lanthanides. The synthesis of metal complexes and their spectroscopic studies are described in some cases; however information on their biological activity is scarce, although the chemoprotective activity of this acid is often related to the coordination or reduction of transition metals and the formation of adducts $[1,8]$. Studies of the structure of CFA complexes with a series of cations, namely $\mathrm{Li}^{+}, \mathrm{Na}^{+}, \mathrm{K}^{+}, \mathrm{Rb}^{+}$, and $\mathrm{Cs}^{+}$, performed in the solid state, show that considered metals affect the molecular structure and electronic charge distribution of the ligand; this changes their biological action, namely their antioxidant activity $[9,10]$. In an aqueous solution, the coordination of metal cations seems to occur preferentially by the hydroxyl groups. Cornard et al. [11,12] described the formation of $\mathrm{Al}(\mathrm{III})$-CFA complexes and, using UV-Vis and synchronous fluorescence spectroscopies, demonstrated that, for example, only the catechol moiety is involved in the formation of $1: 2$ and 1:3 complexes at $\mathrm{pH}=6.5$ [12]. This was also observed for $\mathrm{Cr}(\mathrm{III})$, as the binding of ions takes place through the two phenolic groups of the CFA [13]. Nevertheless, the formation of CFA-Pb(II) metal complexes in aqueous solutions seems to occur directly via carboxylic group [14]. Many other studies on the interaction of CFA toward different metal cations are reported [15,16] but, to our knowledge, no work was reported concerning the study of the complexes formed for CFA/lanthanide(III) systems.

Lanthanides are well-known for their particular chemical properties that lead to their application in several fields, from electronics and physics to medical applications (therapeutics and/or diagnosis) [17]. However, the biological role of lanthanides and their 
impact on living organisms is still poorly understood, although it is well-known that they interact with several biologically relevant ligands [18-20]. Several Ln(III) complexes with organic ligands show interesting pharmacological properties. For example, Kostova and coworkers studied the molecular structure and spectroscopic properties of various derivatives of coumarin and orotic acid (vitamin B13) and their complexes with La(III), Ce(III), Nd(III), Dy(III), and Sm(III), as well as the antioxidant activity of the formed complexes [21-24]. Other authors documented higher antibacterial activity of $\mathrm{Ln}$ (III) (Dy, Sm, Pr, Nd, La, Er, and Gd) complexes with tetradentate Schiff bases when compared to free ligands $[25,26]$. According to the recent review of Cota et al. [27], the antimicrobial activity of ligands is enhanced by the complexation with lanthanide ions, mainly due to the increase in the lipophilicity of the metal complex vs. the free ligand. This helps the penetration through the lipid membranes, disturbing the functioning of the bacterial/fungal cell. Moreover, the anticancer activity of lanthanides was also evaluated and several Eu(III) complexes were synthesized and tested, showing some promising results as new anticancer agents [28-30].

As part of a wider topic which aims to study the relationship between the molecular structure and the biological activity (microbial, cytostatic and antioxidant) of selected phenolic acids and their metal complexes [31-34], we present herein the study of the interaction of CFA towards $\mathrm{Eu}(\mathrm{III})$, and how the complexation influences the antimicrobial and the antioxidative properties of CFA. On a global perspective, we intend to contribute to a better understanding of how coordination with selected metals affects the molecular structure and distribution of the electronic charge of ligands, changing CFA biological activity, including their antioxidant properties. To answer this, we need to exploit several topics: (1) which binding groups of CFA are involved in the coordination of Eu(III), and how this affects the biological activity of the metal complex when compared with the free ligand; (2) how the extension of the conjugated system of double bonds (responsible for the delocalization of the electronic charge) will translate into biological properties, by comparing different benzoic acid derivatives (with a shorter conjugated double bond system) with cinnamic acid derivatives (with a longer double conjugated bond system); (3) which metal parameters have the greatest impact on the increase in the antioxidant properties of ligands due to metal complexation.

Due to the complexity of the systems under study, only a multi-analytical-technique approach can provide sufficient knowledge for answering all of these questions; these can be answered by means of investigation of solution equilibria [35], the correct characterization of the synthesized compounds [36,37], and the assessment of their biological activity [38]. In our previous works, the above-mentioned effects were mainly examined in the solid phase $[32,34,39,40]$. Currently, this paper is also devoted to the study of the chemical equilibria, speciation and sequestering ability of CFA in aqueous solution, as they are of paramount relevance to the evaluation of the biological activity of metal compounds; this is due to modulation of the conditions existing in the media used to perform some of the assays, and at a later stage, inside living organisms. For this reason the chemical equilibria of the Eu(III)/CFA system in an aqueous solution were studied using a multitechnique approach, where potentiometry and UV-Vis spectroscopy measurements were complemented by ${ }^{1} \mathrm{H}-\mathrm{NMR}$ experiments and electrospray-ionization mass spectrometry (ESI-MS) to support the existence of EuL species. The Eu(III)-CFA metal complex was also synthesized and characterized using elemental and thermal analyses, as well as Raman and FT-IR spectroscopy. Moreover, the antioxidant and antimicrobial activity of Eu(III)-CFA was evaluated and compared with CFA action. This was achieved by means of several antioxidant assays based on different mechanisms of action, namely DPPH• (2,2-diphenyl1-picrylhydrazyl) radical, ABTS•+ (2,2-azino-bis(3-ethylbenzothiazoline-6-sulfonic acid), FRAP (ferric reducing antioxidant power), CUPRAC (cupric reducing antioxidant power), and lipid peroxidation assays. The antimicrobial activity against Escherichia coli (Gram(-) bacteria), Bacillus subtilis (Gram(+) bacteria) and Candida albicans (fungi) was also tested, while electrophoretic mobility assays were used to evaluate the interaction of CFA and $\mathrm{CFA} / \mathrm{Eu}(\mathrm{III})$ with the cell membranes of the studied microorganisms. 


\section{Results and Discussion}

\subsection{Molecular Structure of $\left[\mathrm{Eu}(\mathrm{CFA})_{3}\right]$}

The structure of the europium complex was described based on the results of elemental analysis and TGA, combined with spectroscopic studies. For that purpose, FT-IR and FT Raman spectra of CFA and Eu-caffeinate were recorded. The spectroscopic data are presented in Table 1, and the recorded FT-IR spectra are depicted in Figure 1. The vibration bands of the aromatic system have been numbered according to Varsanyi's classification [41]. The spectra of CFA show characteristic bands derived from the stretching vibrations of the carbonyl group $v_{\mathrm{C}=\mathrm{O}}$, present at the values of $1647 \mathrm{~cm}^{-1}\left(\mathrm{IR}_{\mathrm{KBr}}\right), 1634 \mathrm{~cm}^{-1}\left(\mathrm{IR}_{\mathrm{ATR}}\right)$ and $1641 \mathrm{~cm}^{-1}$ (Raman). This band overlaps with the band of the stretching vibrations

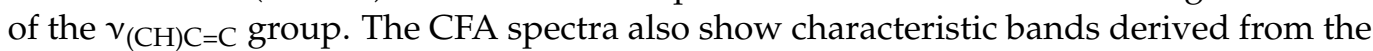
vibrations of the hydroxyl groups attached to the aromatic ring, at ca. $1280 \mathrm{~cm}^{-1}$, being the stretching vibrations of the hydroxyl group $\left(v_{\mathrm{O}-\mathrm{H}}\right)$ present, observed at $3431 \mathrm{~cm}^{-1}$ and $3235 \mathrm{~cm}^{-1}$. When comparing the CFA spectra with those obtained for Eu-caffeinate, the first observation that can be made is that the bands associated with the stretching vibrations of the aromatic ring hydroxyl groups in the europium complex have a significantly reduced intensity compared to these bands in the CFA spectrum. It was also observed that some of the bands associated with the bending vibration of the hydroxyl groups disappeared in the spectra of the europium complex, or were of reduced intensity. This could be the result of the involvement of the hydroxyl groups in the coordination of the metal cation. Furthermore, new characteristic bands related to the vibration of the carboxylate anion appear on the spectrum of the analysed europium complex. These are the bands of symmetric stretching vibrations $v_{\mathrm{S}} \mathrm{COO}^{-}$present at $1409 \mathrm{~cm}^{-1}\left(\mathrm{IR}_{\mathrm{KBr}}, \mathrm{IR}_{\mathrm{ATR}}\right)$ in the europium complex, and bands of symmetric stretching vibrations $v_{\mathrm{as}} \mathrm{COO}^{-}$presented at $1501 \mathrm{~cm}^{-1}\left(\mathrm{IR}_{\mathrm{KBr}}\right)$ and $1499 \mathrm{~cm}^{-1}$ (IR $\left.\mathrm{ATR}\right)$. In addition, the spectra of the tested metal complex show bands associated with vibrations bending in the plane $-\beta_{\mathrm{s}} \mathrm{COO}^{-}$(symmetrical) and $\beta_{\mathrm{as}} \mathrm{COO}^{-}$ (asymmetrical) - and bending out of the plane $\left(\gamma \mathrm{COO}^{-}\right)$(See Table 1$)$. A small shift to lower wavelength is also observed for the bands related to the stretching vibrations of the carbonyl group $\left(v_{\mathrm{C}=\mathrm{O}}\right)$, from $1647 \mathrm{~cm}^{-1}$ to $1630 \mathrm{~cm}^{-1}\left(\mathrm{IR}_{\mathrm{KBr}}\right)$, and $1634 \mathrm{~cm}^{-1}$ to $1629 \mathrm{~cm}^{-1}$ $\left(\mathrm{IR}_{\mathrm{ATR}}\right)$. This may indicate the occurrence of some interaction of the metal cation with the ligand, this time through the carboxyl group.

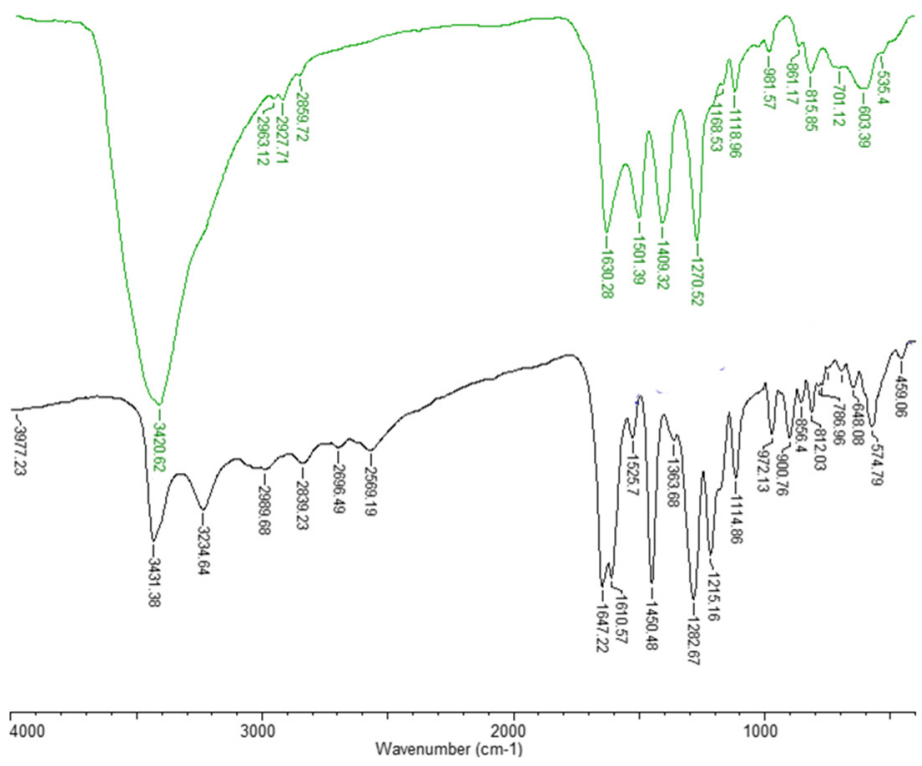

Figure 1. FT-IR spectra (registered in $\mathrm{KBr}$ pellets) for CFA (black) and Eu(III)-caffeinate (green). 
Table 1. The wavenumbers $\left(\mathrm{cm}^{-1}\right)$, intensities and assignments of bands observed in the experimental FT-IR (KBr and ATR) and FT-Raman spectra of CFA and Eu(III)-caffeinate.

\begin{tabular}{|c|c|c|c|c|c|c|}
\hline \multicolumn{3}{|c|}{ CFA } & \multicolumn{2}{|c|}{ Eu(III)-Caffeinate } & \multirow[t]{2}{*}{ Assignment } & \multirow[t]{2}{*}{$\begin{array}{c}\text { Varsanyi's } \\
\text { Designation [41] }\end{array}$} \\
\hline $\mathrm{IR}_{\mathrm{KBr}}$ & $\mathrm{IR}_{\mathrm{ATR}}$ & Raman & $\mathrm{IR}_{\mathrm{KBr}}$ & $\mathrm{IR}_{\mathrm{ATR}}$ & & \\
\hline $3431 \mathrm{~s}^{\mathrm{a}}$ & $3399 \mathrm{~m}$ & & $3421 \mathrm{vs}$ & $3396 \mathrm{~m}$ & $v(\mathrm{OH})_{\mathrm{ar}} \mathrm{b}$ & \\
\hline $3235 \mathrm{~m}$ & $3218 \mathrm{~m}$ & & - & - & $v(\mathrm{OH})_{\mathrm{ar}}$ & \\
\hline $3000 w$ & $3056 \mathrm{~m}$ & 3032 vw & $2963 \mathrm{w}$ & & $v(\mathrm{CH}), v(\mathrm{CH})_{\mathrm{C}=\mathrm{C}}$ & $20 b$ \\
\hline $2839-2569 \mathrm{w}$ & & & & & $v(\mathrm{OH})$ & \\
\hline 1647 vs & $1634 \mathrm{~s}$ & $1641 \mathrm{~m}$ & $1630 \mathrm{~s}$ & $1629 \mathrm{sh}$ & $v(\mathrm{C}=\mathrm{O}), v(\mathrm{CH})_{\mathrm{C}=\mathrm{C}}$ & \\
\hline 1611 vs & $1602 \mathrm{vs}$ & 1613 vs & & - & $v(\mathrm{CC})$ & $8 a$ \\
\hline \multirow[t]{3}{*}{$1526 \mathrm{w}$} & $1526 \mathrm{~m}$ & $1532 \mathrm{vw}$ & & & $v(C C)$ & $8 b$ \\
\hline & & & $1501 \mathrm{~m}$ & 1499 vs & $v_{\mathrm{as}}(\mathrm{COO})$ & \\
\hline & & & & 1505 vs & $v_{\mathrm{as}}(\mathrm{COO})$ & \\
\hline \multirow[t]{2}{*}{1450 vs } & 1442 vs & $1453 \mathrm{vw}$ & & & $v(C C)$ & $19 b$ \\
\hline & & & 1409 s & 1409 s & $v_{\mathrm{s}}(\mathrm{COO})$ & \\
\hline $1364 \mathrm{w}$ & $1362 \mathrm{w}$ & $\begin{array}{l}1353 \mathrm{w} \\
1299 \mathrm{~s}\end{array}$ & & & $\begin{array}{c}v(\mathrm{CC}), \beta(\mathrm{OH}) \\
\beta(\mathrm{OH})\end{array}$ & 14 \\
\hline 1283 vs & $1271 \mathrm{~s}$ & & $1271 \mathrm{~s}$ & $1271 \mathrm{vs}$ & $v(\mathrm{C}-\mathrm{OH})$ & \\
\hline $1215 \mathrm{~s}$ & $1209 \mathrm{~s}$ & & & & $\beta(\mathrm{OH}), \beta(\mathrm{CH})_{\mathrm{C}=\mathrm{C}}$ & \\
\hline $1174 \mathrm{~m}$ & - & $1186 \mathrm{w}$ & $1169 \mathrm{w}$ & $1170 \mathrm{~m}$ & $\beta(\mathrm{CH})$ & $18 \mathrm{a}$ \\
\hline $1115 \mathrm{~m}$ & $1110 \mathrm{~s}$ & $1108 \mathrm{vw}$ & $\begin{array}{c}1119 \mathrm{~m} \\
982 \mathrm{w}\end{array}$ & $\begin{array}{l}1120 \mathrm{~m} \\
980 \mathrm{w}\end{array}$ & $\begin{array}{c}\beta(\mathrm{CH}) \\
\beta_{\mathrm{s}}(\mathrm{COO})\end{array}$ & $18 \mathrm{~b}$ \\
\hline $972 \mathrm{w}$ & $965 \mathrm{~m}$ & 974 vw & $961 \mathrm{w}$ & $977 \mathrm{w}$ & $\gamma(\mathrm{CH})_{\mathrm{C}=\mathrm{C}}, \gamma(\mathrm{CH})$ & $17 \mathrm{~b}$ \\
\hline $936 \mathrm{w}$ & $939 \mathrm{w}$ & & & $932 \mathrm{w}$ & $\gamma(\mathrm{CH})$ & $17 \mathrm{a}$ \\
\hline $901 \mathrm{w}$ & $892 \mathrm{~s}$ & & & & $v(\mathrm{CCO})$ & \\
\hline $856 \mathrm{w}$ & $853 \mathrm{~m}$ & $852 \mathrm{vw}$ & $861 \mathrm{w}$ & $853 \mathrm{vw}$ & $\gamma(\mathrm{CH})$ & 5 \\
\hline \multirow[t]{2}{*}{$812 \mathrm{w}$} & & & & & $\beta(\mathrm{C}=\mathrm{O})$ & \\
\hline & & & $816 \mathrm{w}$ & $823 \mathrm{w}$ & $\alpha(\mathrm{CCC})$ & 1 \\
\hline $801 \mathrm{w}$ & $806 \mathrm{~s}$ & 803 vw & & $793 \mathrm{~m}$ & $\gamma(\mathrm{CH})$ & $10 \mathrm{a}$ \\
\hline \multirow[t]{2}{*}{$787 \mathrm{w}$} & $788 \mathrm{~m}$ & 779 vw & & $756 \mathrm{sh}$ & $\alpha(\mathrm{CCC})$ & 12 \\
\hline & & & $701 \mathrm{w}$ & $695 \mathrm{~m}$ & $\gamma_{\mathrm{s}}(\mathrm{COO})$ & \\
\hline $699 \mathrm{w}$ & $695 \mathrm{w}$ & $686 \mathrm{vW}$ & & & $\gamma(\mathrm{C}=\mathrm{O})$ & \\
\hline $645 \mathrm{w}$ & $642 \mathrm{~m}$ & & & $664 \mathrm{vw}$ & $\varphi(\mathrm{CC})$ & $16 a$ \\
\hline $603 w$ & & 603 vw & $603 \mathrm{w}$ & $595 \mathrm{~s}$ & $\alpha(\mathrm{CCC})$ & $6 a$ \\
\hline $575 \mathrm{~m}$ & & $534 \mathrm{vw}$ & $535 \mathrm{w}$ & & $\gamma(\mathrm{OH})$ & \\
\hline $459 w$ & & $459 \mathrm{vw}$ & $547 \mathrm{vw}$ & $547 \mathrm{~s}$ & $\alpha(\mathrm{CCC})$ & $6 b$ \\
\hline $409 w$ & & $446 \mathrm{vw}$ & $407 \mathrm{vw}$ & & $\varphi(\mathrm{CC})$ & $16 b$ \\
\hline
\end{tabular}

a s-strong; m-medium; w-weak; v-very; sh-shoulder. ${ }^{b}$ the symbol " $v$ " denotes stretching vibrations. " $\beta$ " denotes in-plane bending modes. " $\gamma$ " designates out-of-plane bending modes; " $\varphi(C C C)$ " denotes the aromatic ring out-of-plane bending modes and " $\alpha(\mathrm{CCC})$ " designates the aromatic ring in-plane bending modes.

In an effort to obtain a better insight on the possible structure of the Eu-caffeinate complex, we analysed, in more detail, the changes in the aromatic system of CFA resulting from the coordination to the metal cation. In general, lanthanides, similarly to 3d-transition metals, stabilize the electronic system of the aromatic ring in ligands as benzoates, salicylates, and 3-pyridine carboxylates, resulting from the coordination to the carboxylic group of the benzoate ring [42,43]. This results in substantial changes in the correspondent IR spectra, usually characterized by an increase in the number and intensity of the aromatic system bands, as well as a shift on their wavenumber values, when compared with the free ligand spectra. On the contrary, when the aromatic system is destabilized by the coordination of, for example, alkaline metals, we observe a decrease in intensity in the spectra and a decrease in the wavenumber values of the bands of the aromatic system $[42,43]$. In the particular case of the Eu-caffeinate spectrum, even though we observed a small increase in the wavenumbers of some bands of the aromatic system (e.g., 6b, 17b and 18b, designated according to Varsányi's classification [41]), most of them disappear, or their wavenumber values are shifted towards lower values in the spectrum of $\mathrm{Eu}(\mathrm{III})$-caffeinate when compared to the spectrum of CFA. This may indicate 
that, in this particular case, the coordination of Eu(III) has a destabilizing effect on the aromatic system of CFA, possibly the result of a not so relevant interaction between the carboxylic group and the metal cation. Nevertheless, if it happens, we can predict the type of metal-ligand coordination in the studied Eu(III) complex, based on the criteria described by Nakamoto and McCarthy [44]. According to them, when the difference between the wavenumbers of asymmetric and symmetric vibrations of the $\mathrm{COO}^{-}$group in the IR spectrum of the studied complex $\left(\Delta v\left(\mathrm{COO}^{-}\right)=v_{\mathrm{as}}\left(\mathrm{COO}^{-}\right)-v_{\mathrm{s}}\left(\mathrm{COO}^{-}\right)\right)$is much smaller than the difference between the wavenumbers of the same bands for sodium salt, then there is presumably a bidentate chelating type of coordination. A $\Delta v\left(\mathrm{COO}^{-}\right)_{\text {complex }}$ equal to or lower than $\Delta v\left(\mathrm{COO}^{-}\right)_{\mathrm{Na}}$ salt may be indicative of a bidentate bridging coordination type. Finally, when $\Delta v\left(\mathrm{COO}^{-}\right)_{\text {complex }}$ is much higher than $\Delta v\left(\mathrm{COO}^{-}\right)_{\mathrm{Na}}$ salt, we may be in the presence of a monodentate coordination type. As such, in the case of the metal complex of Eu(III) with CFA, the analysis of the asymmetric and symmetric stretching vibrations of the carboxylate anion, in relation to the analogous vibrations in the sodium salt (Figure S1), indicates a bidentate coordination type for carboxylic moiety chelation $\left(\Delta v\left(\mathrm{COO}^{-}\right)_{\text {complex }}=92 \mathrm{~cm}^{-1}<<v\left(\mathrm{COO}^{-}\right)_{\mathrm{Na} \text { salt }}=147 \mathrm{~cm}^{-1}\right)$. Nevertheless, it is worth mentioning that, if the coordination of CFA molecules to the central europium ion occurs through the hydroxyl groups of the aromatic ring, a carboxylate anion is formed, in which the carbon-oxygen bonds are aligned. Hence, the position of the asymmetric and symmetric stretching bands of the carboxylate anion may be similar to those of a CFA molecule that coordinates $\mathrm{Eu}(\mathrm{III})$ via the carboxyl group, also resulting in a small $\Delta v\left(\mathrm{COO}^{-}\right)_{\text {complex }}$.

For comparative purposes, $\mathrm{Eu}(\mathrm{III})$ complexes of cinnamic and $p$-coumaric acids were also synthesized, and the metal complexes' spectroscopic data, as well as those of their corresponding ligands are reported in Table 2.

Table 2. The wavenumbers $\left(\mathrm{cm}^{-1}\right)$, intensities and assignments of bands observed in the experimental FT-IR (KBr and ATR) spectra of cinnamic acid, Eu(III)-cinnamate and p-coumaric acid, and Eu(III)p-coumarate.

\begin{tabular}{|c|c|c|c|c|c|}
\hline $\mathrm{IR}_{\mathrm{KBr}}$ & $\mathrm{IR}_{\mathrm{ATR}}$ & $\mathrm{IR}_{\mathrm{KBr}}$ & $\mathrm{IR}_{\mathrm{ATR}}$ & Assignment & $\begin{array}{c}\text { Varsanyi's } \\
\text { Designation [41] }\end{array}$ \\
\hline \multicolumn{2}{|c|}{ Cinnamic acid } & \multicolumn{2}{|c|}{$\mathrm{Eu}(\mathrm{III})$-cinnamate } & & \\
\hline 1684 vs & 1667 vs & - & - & $v(\mathrm{C}=\mathrm{O})$ & \\
\hline- & - & $1536 \mathrm{~s}$ & $1520 \mathrm{~s}$ & $v_{\mathrm{as}}\left(\mathrm{COO}^{-}\right)$ & \\
\hline $1494 \mathrm{w}$ & $1492 \mathrm{~m}$ & - & 1507 s & $\beta(\mathrm{CH})_{\text {aro. }}$ & $19 \mathrm{a}$ \\
\hline $1448 \mathrm{~m}$ & $1449 \mathrm{~m}$ & $1448 \mathrm{~s}$ & $1446 \mathrm{~m}$ & $v(\mathrm{CC})_{\text {aro }}+\beta(\mathrm{CH})_{\text {aro. }}$ & $19 \mathrm{~b}$ \\
\hline- & - & 1412 vs & $1399 \mathrm{~s}$ & $v_{\mathrm{s}}\left(\mathrm{COO}^{-}\right)$ & \\
\hline 1073 w & $1071 \mathrm{~m}$ & $1069 \mathrm{w}$ & $1071 \mathrm{vw}$ & $v(\mathrm{CC})_{\text {aro }}+\beta(\mathrm{CH})_{\text {aro. }}$ & $18 b$ \\
\hline $1025 \mathrm{w}$ & $1030 \mathrm{w}$ & $1029 \mathrm{w}$ & $1026 \mathrm{vw}$ & $v(\mathrm{CC})_{\text {aro }}+\beta(\mathrm{CH})_{\text {aro. }}$ & $18 \mathrm{a}$ \\
\hline \multicolumn{2}{|c|}{$p$-coumaric acid } & \multicolumn{2}{|c|}{$\mathrm{Eu}(\mathrm{III})-p$-coumarate } & & \\
\hline 3422 vs & $3330 \mathrm{w}$ & 3423 vs & - & $v(\mathrm{OH})_{\text {aro. }}$ & \\
\hline $\begin{array}{l}2924 \mathrm{w}^{-} \\
2580 \mathrm{w}\end{array}$ & $2944 \mathrm{w}-2379 \mathrm{~m}$ & $\begin{array}{l}2924 \mathrm{w}^{-} \\
2613 \mathrm{vw}\end{array}$ & $2804 \mathrm{~m}$ & $v(\mathrm{OH})_{\text {aro. }}$ & \\
\hline $1671 \mathrm{~s}$ & 1664 vs & - & - & $v(\mathrm{C}=\mathrm{O})$ & \\
\hline- & - & $1559 \mathrm{~m}$ & $1559 \mathrm{~m}$ & $v_{\mathrm{as}}\left(\mathrm{COO}^{-}\right)$ & \\
\hline $1511 \mathrm{~m}$ & $1503 \mathrm{~m}$ & $1512 \mathrm{~s}$ & 1502 vs & $v(C C)_{\text {aro }}$ & $19 a$ \\
\hline $1448 \mathrm{~m}$ & $1440 \mathrm{~s}$ & $1439 \mathrm{~m}$ & 1442 m & $v(C C)_{\text {aro }}$ & $19 b$ \\
\hline- & - & $1409 \mathrm{~s}$ & - & $v_{\mathrm{s}}\left(\mathrm{COO}^{-}\right)$ & \\
\hline $1106 \mathrm{w}$ & $1105 \mathrm{~m}$ & $1104 \mathrm{w}$ & 1107 m & $\beta(\mathrm{CH})$ & $18 \mathrm{~b}$ \\
\hline 1063 w & - & - & - & $\beta(\mathrm{CH})$ & $18 \mathrm{a}$ \\
\hline
\end{tabular}

Cinnamic acid does not contain hydroxyl groups in the aromatic ring, while $p$-coumaric acid has one hydroxyl group in the para-position of the aromatic ring. Based on the chemical structure of the ligands and, once again, following Nakamoto's criteria [44], we could predict the type of coordination of $\mathrm{Eu}$ (III) by $p$-coumaric acid and cinnamic acid. The bands resulting from the vibrations of the hydroxyl group of the aromatic $p$ - 
coumaric acid system on the spectrum of the complex do not undergo significant changes in the metal complex; this proves that it is not involved in the metal coordination. Furthermore, taking into account $\Delta v\left(\mathrm{COO}^{-}\right)=v_{\mathrm{as}}\left(\mathrm{COO}^{-}\right)-v_{\mathrm{S}}\left(\mathrm{COO}^{-}\right)$differences for the sodium salt of cinnamic acid [45] and the europium complex, it can be assumed that there is a double-bridge-chelating coordination between the central ion and the ligand $\left(\left(\Delta v\left(\mathrm{COO}^{-}\right)_{\text {complex }}=124=\Delta v\left(\mathrm{COO}^{-}\right)_{\mathrm{Na} \text { salt }}=124\right.\right.$ [45]. In the case of the europium complex with $p$-coumaric acid, $\left(\Delta v\left(\mathrm{COO}^{-}\right)_{\text {complex }}=150>\Delta v\left(\mathrm{COO}^{-}\right)_{\mathrm{Na} \text { salt }}=135[46]\right.$, and so the metal-ligand coordination by the carboxylic group should be monodentate. For both of these acids, metal complexation occurs favourably via the carboxyl group.

Therefore, we can try to propose a structure for the synthesized Eu(III)-caffeinate, also having as reference the various examples reported of metal complexes with hydroxybenzoic acids. In particular, in the metal complex of Eu(III) with gallic acid, described by Lin et al. [47], both the hydroxyl groups and the carboxyl group of gallic acid are involved in the metal-ligand coordination, but lead to the formation of an interesting 3D metalorganic framework. Another example is the study described by Dan et al. [48] of strontium complexes with dihydroxybenzoic acids. In this case, the complexation of strontium occurs through the participation of hydroxyl groups attached to the aromatic ring. The elemental analysis (EA) of the isolated solid indicated the occurrence of a total of five molecules of water per molecule of metal complex. This result was confirmed by thermal gravimetric analysis (TGA). During TGA two different steps of weight loss were observed: first at 40-110 ${ }^{\circ} \mathrm{C}$, which we attributed to the thermal dehydration and loss of 2 water molecules (exp $6.32 \%$, calc $5.75 \%$ ), followed by a second one at $120-220{ }^{\circ} \mathrm{C}$, corresponding to 3 water molecules coordinated to the metallic centre (exp $7.53 \%$, calc $7.48 \%$ ). On the basis of all of these considerations, we can propose the following structure for the $\mathrm{Eu}(\mathrm{III})$-caffeinate complex (Figure 2), corresponding to the molecular formula $\left[\mathrm{Eu}(\mathrm{CFA})_{3}\left(\mathrm{H}_{2} \mathrm{O}\right)_{3}\right] \cdot 2 \mathrm{H}_{2} \mathrm{O}$.

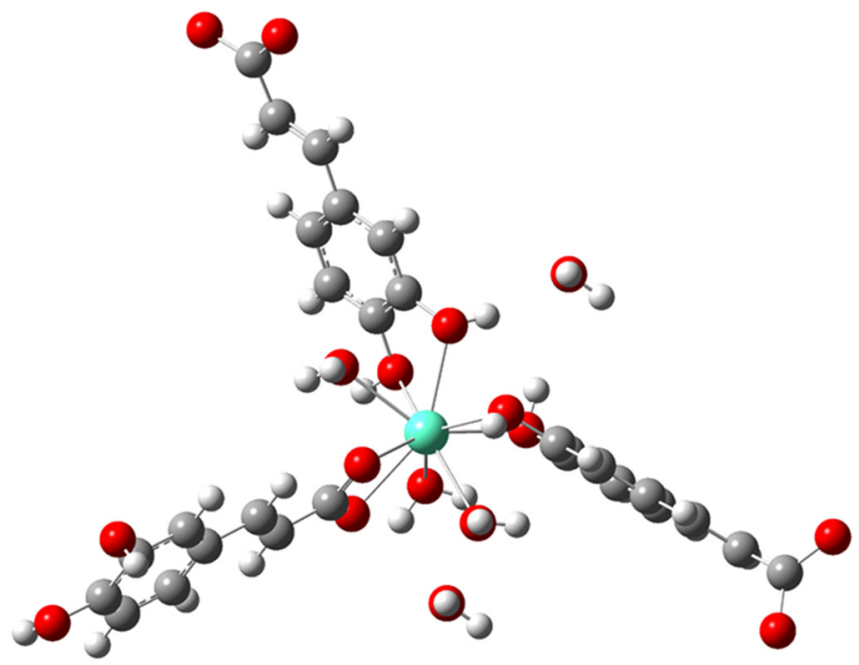

Figure 2. Proposed structure for the synthesized Eu(III)-caffeinate metal complex.

\subsection{Solution Equilibrium Studies}

\subsubsection{Acid-Base Properties of CFA and $\mathrm{Eu}^{3+}$}

The acid-base properties of CFA were studied and the protonation constants were determined experimentally by potentiometric titrations under the defined conditions of temperature, medium, and ionic strength (i.e., $T=298.15 \pm 0.1 \mathrm{~K}$ and $I=0.2 \mathrm{~mol} \cdot \mathrm{dm}^{-3}$ in $\left.\mathrm{KCl}_{(\mathrm{aq})}\right)$. CFA has three functional groups that can be involved in various protonation/deprotonation equilibria, namely one carboxylic and two hydroxyl groups (forming a catecholate unit). In the $\mathrm{pH}$ range investigated $(2<\mathrm{pH}<12)$, three protonation steps can be observed, and the corresponding protonation constants are presented in Table 3. 
Table 3. Protonation constants ${ }^{\text {a }}$ of CFA in $\mathrm{KCl}_{(\mathrm{aq})}$ at $I=0.2 \mathrm{~mol} \cdot \mathrm{dm}^{-3}$ and $T=298.15 \mathrm{~K}$.

\begin{tabular}{ccc}
\hline Species & $(p: q: r)$ & $\log \beta_{p q r}{ }^{\mathbf{a}}\left(\log K_{\mathbf{0 1 r}}\right)^{\mathbf{b}}$ \\
\hline $\mathrm{LH}$ & $0: 1: 1$ & $11.93 \pm 0.08$ \\
& & $20.59 \pm 0.08(8.66)$ \\
$\mathrm{LH}_{2}$ & $0: 1: 2$ & $(20.47 \pm 0.06)^{\mathrm{c}}$ \\
& & $(20.9 \pm 0.3)^{\mathrm{d}}$ \\
$\mathrm{LH}_{3}$ & $0: 1: 3$ & $24.92 \pm 0.01(4.33)$ \\
& & $(24.97 \pm 0.03)^{\mathrm{c}}$ \\
& & $(25.3 \pm 0.3)^{\mathrm{d}}$ \\
\hline
\end{tabular}

a $\log \beta_{p q r}$ refers to the equilibrium: $p \mathrm{M}+q \mathrm{~L}+r \mathrm{H}^{+}=\mathrm{M} p \mathrm{~L} q \mathrm{H} r{ }^{\mathrm{b}} \log K_{01 r}$ refers to the equilibrium: $\mathrm{H}^{+}+\mathrm{LH}_{r-1}=\mathrm{LH}_{r}, \pm \mathrm{SD} ;{ }^{c}$ values obtained from spectrophotometric measurements; ${ }^{\mathrm{d}}$ values obtained from ${ }^{1} \mathrm{H}-\mathrm{NMR}$ measurements.

Considering CFA's molecular structure and based on several reported studies $[15,49]$ the hydroxyl groups should be the first to be protonated $(\log K=11.93 \pm 0.02$ and $8.66 \pm 0.08)$, being the carboxylic group expected to be protonated as last, with an observed $\log K$ value of $4.33 \pm 0.01$, in the experimental conditions adopted. The obtained values are in full agreement with those reported in the literature by Bizri et al. [49] $\left(\log K_{011}=11.80\right.$, $\left.\log K_{012}=8.66, \log K_{013}=4.45\right)$. Based on the determined protonation constants, the distribution diagram of CFA species in different protonation states can be drawn, and it is presented in Figure 3.

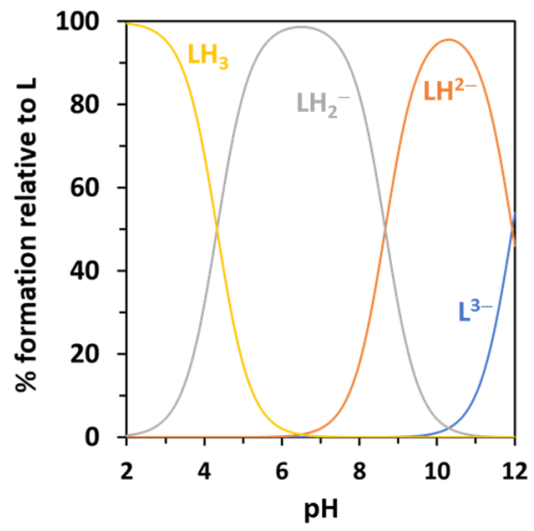

Figure 3. Distribution diagram of caffeinate species as a function of $\mathrm{pH}$ in $\mathrm{KCl}_{(\mathrm{aq})}$ at $I=0.2 \mathrm{~mol} \cdot \mathrm{dm}^{-3}$ and $T=298.15 \mathrm{~K} . c_{\mathrm{L}}=1 \mathrm{mmol} \cdot \mathrm{dm}^{-3}$.

The fully protonated species, $\left[\mathrm{LH}_{3}\right]$, is the major species at $\mathrm{pH}<4$, when the deprotonation of the carboxylic acid starts, leading to the formation of $\left[\mathrm{LH}_{2}\right]^{-}$species, which is the major species at neutral $\mathrm{pH}$. At $\mathrm{pH}>8$, the stepwise deprotonation of the catecholate unit starts, being the fully deprotonated species present only in very basic conditions $(\mathrm{pH}>11)$.

Independent spectrophotometric titrations were also performed, and the fitting of the experimental data using the HypSpec2014 program [50] confirmed the protonation constants determined by potentiometric titrations (see Table 3). HypSpec2014 program fitting also allows the spectrophotometric characterization of the system calculating the molar absorptivity of each CFA species (Figure S2). These data (reported in Table S2) are in excellent agreement (practically coincident, within the uncertainty) with the literature [15] The clear attribution of the protonation steps to the specific basic groups of CFA was achieved using ${ }^{1} \mathrm{H}-\mathrm{NMR}$ titrations. Several measurements were performed where the individual ${ }^{1} \mathrm{H}-\mathrm{NMR}$ spectra were recorded from CFA aqueous solutions at different $\mathrm{pH}$ values (see Figure S3). The individual chemical shift of each proton for each chemical species and their variations in the various protonation steps, graphically represented in Figure 4c (the experimental spectra can be seen in Figure S2 and the corresponding chemical shifts are reported in Table S1), provide support to the attribution of the protonation steps 
to specific basic groups. In particular, the variation of the individual chemical shift of $\mathrm{H}_{\mathrm{b}}$ confirms the deprotonation of the carboxylic acid at $\mathrm{pH} \approx 4$ (with the calculated $\mathrm{p} K_{\mathrm{a}}$ of $4.4 \pm 0.1$, see Table 3 ) and the catecholate deprotonation that occurs at $\mathrm{pH}>8$, evidenced by the change in the chemical shift of $\mathrm{H}_{\mathrm{c}}, \mathrm{H}_{\mathrm{d}}$ and $\mathrm{H}_{\mathrm{e}}$. The obtained data (the chemical shift vs. $\mathrm{pH})$ were fitted by HypNMR software [51] to determine the theoretical chemical shifts of each species (Table 4) as well as the protonation constants of CFA (Table 3). Data reported in Table 3 describe optimal agreement between potentiometric, spectrophotometric and NMR results. Even though the $\log \beta$ values obtained from NMR data are slightly different from the values obtained by potentiometric and spectrophotometric measurements (ca. $0.5 \log$ units), they agree within the uncertainty of the calculation. This result is expected due to the reduced number of experimental data that can reasonably be collected by NMR titrations.

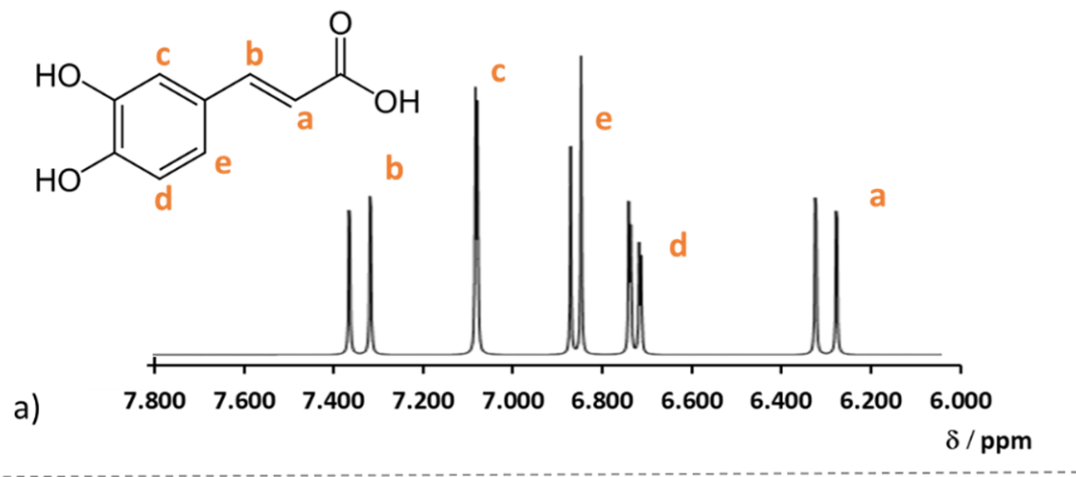

b)

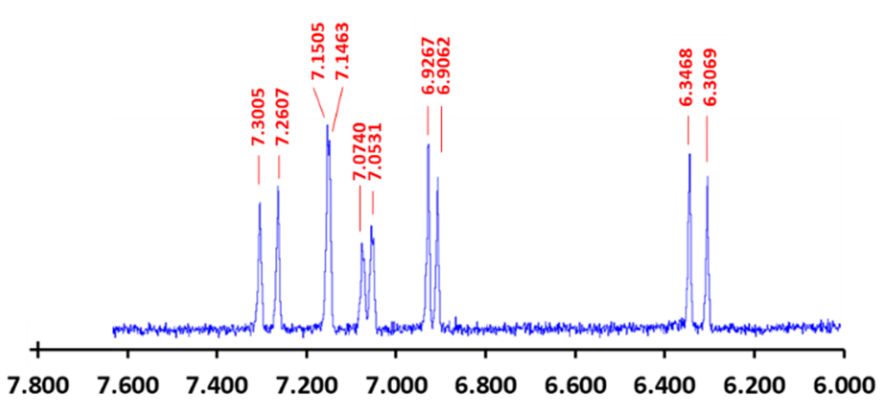

\section{$\delta / \mathrm{ppm}$}

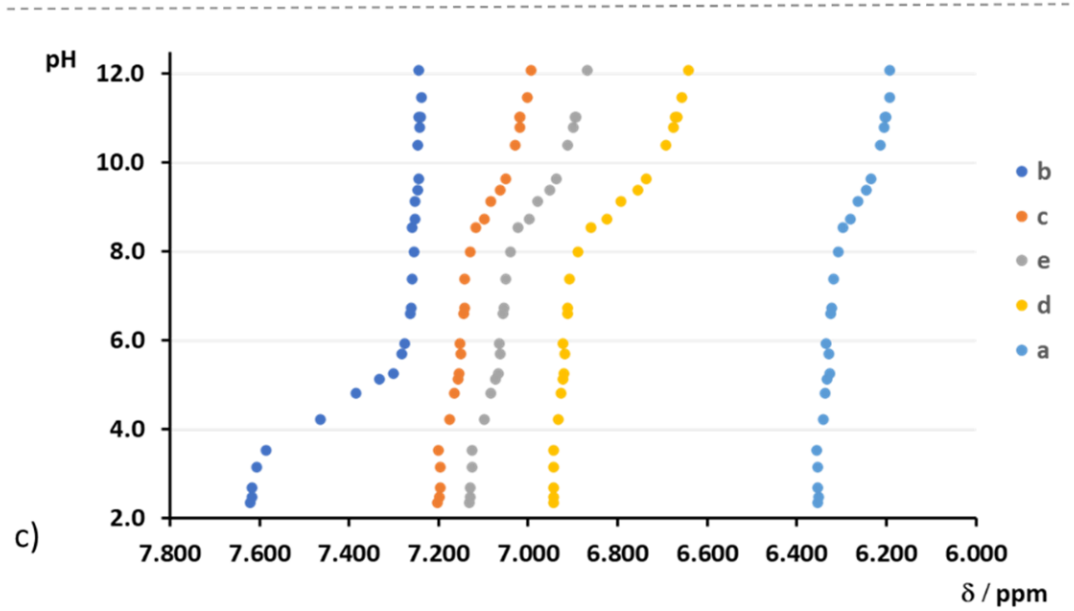

Figure 4. Representation of ${ }^{1} \mathrm{H}-\mathrm{NMR}$ titration: (a) ${ }^{1} \mathrm{H}-\mathrm{NMR}$ spectra of CFA calculated by ChemDraw software and corresponding peak attribution; (b) experimental ${ }^{1} \mathrm{H}-\mathrm{NMR}$ spectra of CFA $\left(c_{\mathrm{CFA}}=10^{-3} \mathrm{~mol} \cdot \mathrm{dm}^{-3}, \mathrm{pH}=5.7\right)$; (c) representation of the chemical shifts of each assigned peak obtained from experimental spectra recorded at different $\mathrm{pH}$ values. 
Table 4. Calculated chemical shift $(\delta / \mathrm{ppm})$ of different (de)protonated species of $\mathrm{CFA}$, in $\mathrm{KCl}_{(\mathrm{aq})}$ at $I=0.2 \mathrm{~mol} \cdot \mathrm{dm}^{-3}$ and $T=298.15 \mathrm{~K}$.

\begin{tabular}{|c|c|c|c|c|}
\hline \multirow{2}{*}{ Nucleus } & \multicolumn{4}{|c|}{$\delta / p p m$} \\
\hline & L & LH & $\mathrm{LH}_{2}$ & $\mathrm{LH}_{3}$ \\
\hline $\mathrm{H}_{\mathrm{b}}$ & 7.2419 & 7.2429 & 7.2612 & 7.6202 \\
\hline $\mathrm{H}_{\mathrm{C}}$ & 6.9927 & 7.035 & 7.1463 & 7.1989 \\
\hline $\mathrm{H}_{\mathrm{e}}$ & 6.8656 & 6.918 & 7.0582 & 7.1294 \\
\hline $\mathrm{H}_{\mathrm{d}}$ & 6.6373 & 6.701 & 6.9168 & 6.9433 \\
\hline $\mathrm{H}_{\mathrm{a}}$ & 6.1865 & 6.2177 & 6.3258 & 6.3534 \\
\hline
\end{tabular}

As well as it happens for the ligands, even when studying equilibria involving metal cations, their acid-base properties (i.e., their hydrolysis) must be considered in the speciation model, since many hydrolytic species, including polynuclear and mixed ones $[52,53]$ may be formed, significantly affecting all other equilibria. In the case of $\mathrm{Eu}^{3+}$ (and other $\mathrm{Ln}^{3+}$ ions), the nature and stability of these species is still questionable. While the formation of the first $[\mathrm{Ln}(\mathrm{OH})]^{2+}$ species is nowadays well defined, and its hydrolysis constants may be easily found in literature in a wide range of conditions, few or no reliable data are available in relation to the nature and stability of other species. That is why Ekberg and Brown, who authored one of the most recent compilations of the hydrolysis constants of metal cations [54], suggest to include only the $[\mathrm{Ln}(\mathrm{OH})]^{2+}$ species in the speciation models for $\mathrm{Ln}^{3+}$, and for $\mathrm{Eu}^{3+}$ in particular. Concerning further hydrolytic $\mathrm{Eu}^{3+}$ species (mainly $\left[\mathrm{Eu}(\mathrm{OH})_{2}\right]^{+}$and $\left.\left[\mathrm{Eu}(\mathrm{OH})_{3}\right]\right)$, the same authors speculate about the (un)reliability of values reported in literature for their hydrolysis constants, but not about their existence. In agreement with Ekberg and Brown, though we also believe that the formation of further $\left[\mathrm{Eu}_{\mathrm{p}}(\mathrm{OH})_{\mathrm{r}}\right]$ species is highly probable, and due to the uncertainty about the nature and stability of other $\mathrm{Eu}^{3+}$ hydrolytic species than $[\mathrm{Eu}(\mathrm{OH})]^{2+}$, we followed these authors' recommendation to consider only the latter species in the model. As such, in this work $\log$ we used $\beta_{10-1}=-8.02$, calculated by Klungness and Byrne [55], who accurately investigated the first hydrolysis of several $\mathrm{Ln}^{3+}$ cations within wide ionic strength and temperature ranges.

\subsubsection{Formation and Stability of $\mathrm{Eu}(\mathrm{III})$-CFA Species}

For the study of the $\mathrm{Eu}^{3+} / \mathrm{CFA}$ system, several independent potentiometric and UVVis spectrophotometric titrations were performed, at different Eu:CFA ratios in favour of the ligand, in order to try to enhance the possible formation of $\mathrm{Eu}_{p} \mathrm{~L}_{q} \mathrm{H}_{r}{ }^{(3 p-3 q+r)}$ species with $q>1$. The analysis of the obtained data shows that only 1:1 species are formed in the solution under our experimental conditions. The analysis of the potentiometric curves (Figure 5) shows that $\mathrm{Eu}^{3+}$ coordination by CFA starts at $\mathrm{pH}>6$, only when the deprotonation of the first catecholate hydroxyl group starts. This is evident by the superimposition of the potentiometric curves of $\mathrm{Eu}^{3+} / \mathrm{CFA}$ systems onto those of the free ligand. This is partial evidence that the carboxylate group, the first to be deprotonated, is not significantly involved in the coordination of the metal cation. Upon increasing $\mathrm{pH}$, two more protons are subsequently displaced from the catecholate moiety, resulting in EuL type complexes, in agreement with several reported chelation studies of CFA-type ligands $[15,56,57]$. Furthermore, it is not surprising that the coordination of the lanthanide cation by the catecholate unit is preferred, as a five membered chelate ring is formed; this is a well-known coordination arrangement with higher stability when compared to the fourmembered chelate rings that would be formed upon coordination via the carboxylic group. 


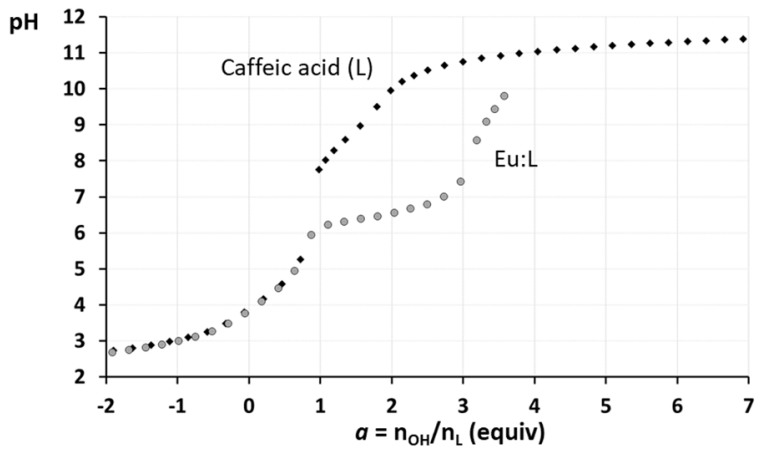

Figure 5. Representative potentiometric titration curves of CFA in the absence and presence of $\mathrm{Eu}^{3+}$ ions at 1:1 metal-to-ligand ratio (negative abscissae refers to the titration of strong acid added to the solutions to lower starting $\mathrm{pH}$ ).

From the analysis of the potentiometric data, we could only determine the complex formation constant of $[\mathrm{Eu}(\mathrm{CFA})]$ species, with a $\log \beta_{110}=10.52 \pm 0.02$, due to the formation of sparingly soluble species at $\mathrm{pH} \approx 7.0-7.5$. This problem was partially solved by using UV-Vis spectrophotometric titrations, which gave us the possibility to work at lower concentrations, allowing measurements until $\mathrm{pH} \approx 10.5-11$, without evident precipitation. The use of UV-Vis spectroscopy also complemented the potentiometric measurements, allowing confirmation of the speciation model and double-checking of the formation constants determined. Several spectrophotometric titrations were performed at different M:L ratios (an example of one titration realized at a 1:1 ratio can be seen in Figure 6a). The analysis of UV-Vis spectra was not so straightforward, since there is no specific band resulting from the coordination with $\mathrm{Eu}^{3+}$. As such, we could only follow the changes on the ligand bands. However, a careful analysis of the UV-Vis spectra showed that an increase of $\mathrm{pH}$ leads to a bathochromic spectral shifting of the ligand peak. This was not surprising as it was also observed on the titrations of CFA alone, as a result of the deprotonation of the catecholate and carboxylic groups (see Figure S2). Nevertheless, in the presence of $\mathrm{Eu}^{3+}$ cation, the observed shift is followed by a decrease in the intensity of the spectra, which can be attributed to the coordination of the chromophore catechol moiety. Using HypSpec2014 software [50] we could process the obtained data, confirming the formation of the neutral [EuL] species. The possibility to investigate a wider (higher) $\mathrm{pH}$ range than that possible by potentiometry allowed further determination of the formation of the $[\mathrm{EuL}(\mathrm{OH})]^{-}$hydroxospecies, resulting from the deprotonation of one water molecule from the [EuL] complex. The stability constants of $[\mathrm{EuL}]$ and $[\mathrm{EuL}(\mathrm{OH})]^{-}$species are presented in Table 5, the former showing a perfect agreement between values obtained by both potentiometry and UV-Vis spectrophotometry. The molar absorbance spectra of these species were also calculated, and they are depicted in Figure $6 \mathrm{~b}$.

The formation of the $[\mathrm{EuL}]$ and $[\mathrm{Eu}(\mathrm{L}) \mathrm{OH}]^{-}$species was also confirmed by ESI-MS measurements. Several samples were analysed, using different M:L ratios, in both positive and negative polarity modes. On negative mode spectra, a peak at $\mathrm{m} / \mathrm{z}=178.95$ (Figure S4a) was observed, representative of the mono charged species $\mathrm{LH}_{2}{ }^{-}\left(\mathrm{C}_{9} \mathrm{H}_{7} \mathrm{O}_{4}{ }^{-}, \mathrm{m} / \mathrm{z}=179.16\right)$, but also a peak at $m / z=347.00$ (Figure S4b), which can be assigned to the $[\mathrm{EuL}(\mathrm{OH})]^{-}$ $\left(\mathrm{C}_{9} \mathrm{H}_{6} \mathrm{O}_{5} \mathrm{Eu}^{-}, m / z=346.11\right)$ species. The presence of the $[\mathrm{EuL}]$ species in the system was confirmed by a signal in the positive mode at $\mathrm{m} / z=370.90$ (Figure 7), corresponding to the $\mathrm{K}^{+}$adduct of the mentioned species $\left([\mathrm{Eu}(\mathrm{L})]+\mathrm{K}^{+}, \mathrm{C}_{9} \mathrm{H}_{5} \mathrm{O}_{4} \mathrm{EuK}^{+}, m / z=368.20\right)$. 
(a)
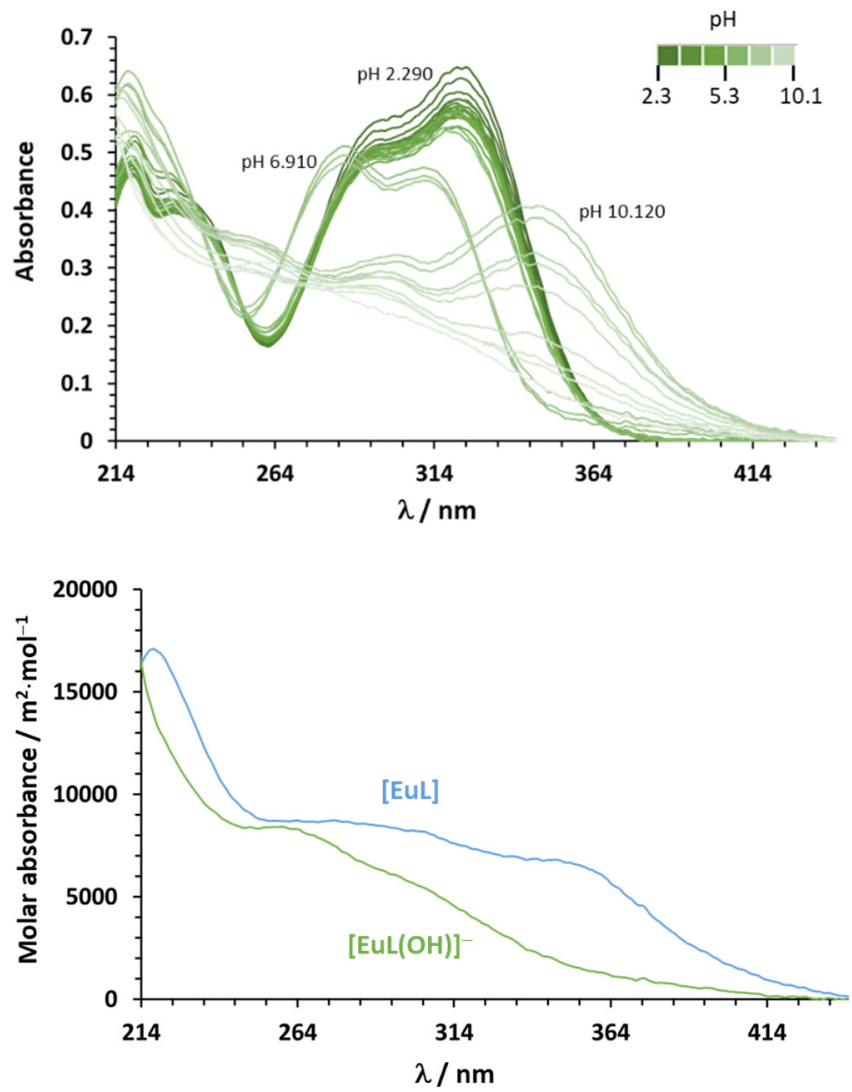

(b)

Figure 6. (a) Experimental absorption spectra of $\mathrm{Eu}^{3+} / \mathrm{CFA}$ system at 1:1 ratio, measured at different $\mathrm{pH}$ values, $c_{\mathrm{CFA}}=4 \times 10^{-5} \mathrm{~mol} \cdot \mathrm{dm}^{-3}$, in $I=0.2 \mathrm{~mol} \cdot \mathrm{dm}^{-3} \mathrm{KCl}_{(\mathrm{aq})}$ and $T=298.15 \mathrm{~K}$; (b) calculated molar absorbance spectra for the $[\mathrm{EuL}]$ and $[\mathrm{EuL}(\mathrm{OH})]^{-}$species.

Table 5. Eu(IIII)/CFA complex formation constants in $\mathrm{KCl}_{(\mathrm{aq})}$ at $I=0.2 \mathrm{~mol} \cdot \mathrm{dm}^{-3}$ and $T=298.15 \mathrm{~K}$.

\begin{tabular}{ccc}
\hline Species & $(p: q: r)$ & $\log \beta_{p q r}{ }^{a}$ \\
\hline EuL & $1: 1: 0$ & $10.52 \pm 0.02$ \\
{$[\mathrm{EuL}(\mathrm{OH})]^{-}$} & $1: 1:-1$ & $(10.57 \pm 0.03)^{\mathrm{b}}$ \\
& & $(0.03 \pm 0.05)^{\mathrm{b}}$ \\
\hline
\end{tabular}

${ }^{a} \log \beta_{p q r}$ refers to the equilibrium: $p \mathrm{Eu}+q \mathrm{~L}+r \mathrm{H}^{+}=\mathrm{Eu}_{p} \mathrm{~L}_{q} \mathrm{H}_{r} \pm \mathrm{SD} ;{ }^{b}$ values obtained from the fitting of the spectrophotometric measurements.

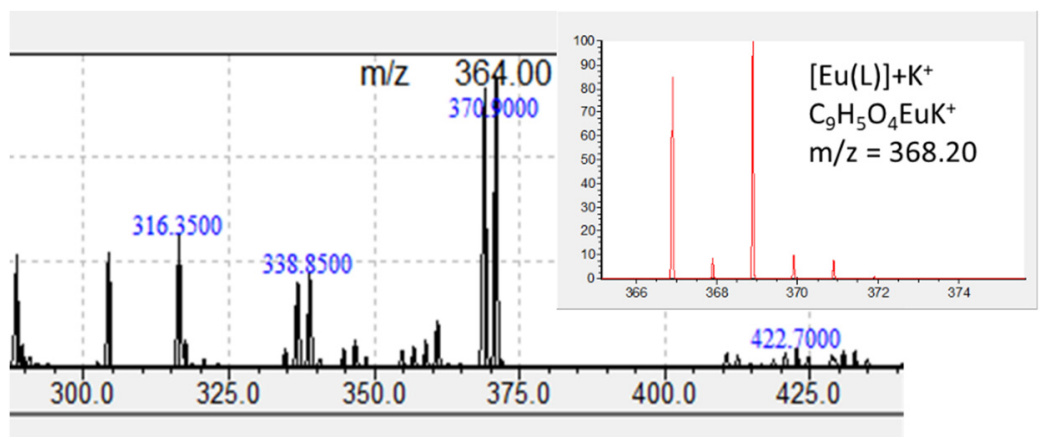

Figure 7. Experimental and theoretical (inset) ESI-MS spectra of the $[\mathrm{Eu}(\mathrm{L})]+\mathrm{K}^{+}$species in the $\mathrm{Eu}^{3+} / \mathrm{CFA}$ system in aqueous solution.

The mixed hydroxo-species $[\mathrm{EuL}(\mathrm{OH})]^{-}$is very likely to be formed, particularly in relation to the fact that, as discussed above, $\mathrm{Eu}^{3+}$ may form further hydrolytic species 
in the $\mathrm{pH}$ of existence of $[\mathrm{EuL}(\mathrm{OH})]^{-}$complexes. For the sake of correctness, it must be stated that the above-discussed exclusion from the model of other $\operatorname{Eu}_{p}(\mathrm{OH})_{r}$ species than $[\mathrm{Eu}(\mathrm{OH})]^{2+}$ (especially the possible $\left[\mathrm{Eu}(\mathrm{OH})_{2}\right]^{+}$and / or $\left[\mathrm{Eu}(\mathrm{OH})_{3}\right]$ species) could lead to a slight overestimation of the stability constant of $[\mathrm{EuL}(\mathrm{OH})]^{-}$species. Nevertheless, it must be taken into account that, as it is, the proposed speciation model perfectly interprets the experimental observations, giving consistent results both by potentiometric and spectrophotometric investigations. Therefore, the proposed speciation model for the $\mathrm{Eu}^{3+} / \mathrm{CFA}$ has to be regarded as reliable as soon as the hydrolytic scheme of $\mathrm{Eu}^{3+}$ is consistent; on the other hand, although this does not represent unequivocable proof of non-existence, further deprotonated $\left[\mathrm{EuL}(\mathrm{OH})_{r}\right]$ species, with $r>1$, were not even observed during ESI-MS experiments in solutions with a very high $\mathrm{pH}$. However, this discussion highlights the absolute need for further investigations on the hydrolysis of $\mathrm{Eu}^{3+}$ and other $\mathrm{Ln}^{3+}$ cations, especially considering recent large numbers of speciation studies of aqueous systems involving them. These studies are ongoing, and will be the subject of future works.

Finally, it is also worth noting that the possibility of the formation of species in which the coordination of $\mathrm{Eu}^{3+}$ metal cations takes place by both the carboxyl and catechol sitesleading to the formation of oligomeric structures - was also taken into account during data analysis, as it is a common observation of the binding of caffeic acid and some derivatives of various divalent metal ions $[17,56,58]$. Nevertheless, the formation of this type of species was neither observed by potentiometry and spectrophotometry, nor by ESI-MS.

\subsubsection{Chemical Speciation and Sequestering Ability}

Considering the chemical speciation of the CFA-Eu ${ }^{3+}$ system, we can see from Figure 8 that the coordination starts at $\mathrm{pH}>6$ with the formation of the [EuL] species; this remains the dominant species until $\mathrm{pH} \approx 9$, where the formation of the $[\mathrm{EuL}(\mathrm{OH})]^{-}$becomes significant (represented using a dashed line, as it was only detected on UV-Vis spectrophotometric measurements).

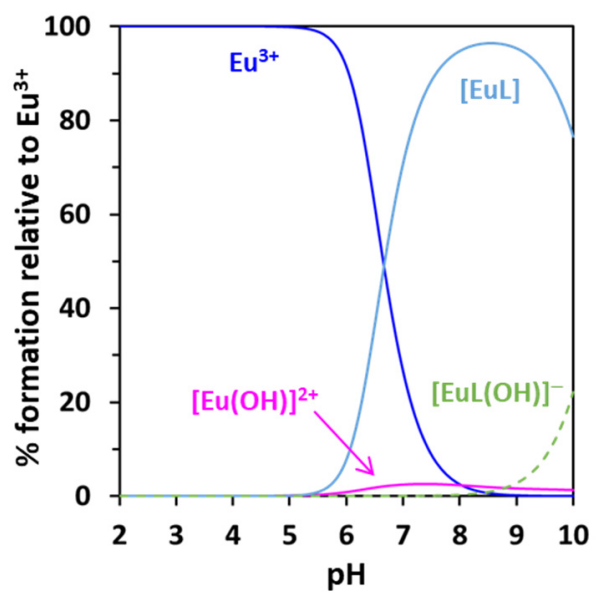

Figure 8. Distribution diagram of the $\mathrm{Eu}_{\mathrm{p}} \mathrm{L}_{\mathrm{q}} \mathrm{H}_{\mathrm{r}}$ species as a function of $\mathrm{pH}$ in the $\mathrm{Eu}^{3+} / \mathrm{CFA}$ system $\left(c_{\mathrm{CFA}}=c_{\mathrm{Eu} 3+}=1 \mathrm{mmol} \cdot \mathrm{dm}^{-3}\right)$, drawn using the determined UV-Vis set of constants. Dash line is used for the species detected only on UV-Vis spectrophotometric measurements.

From the distribution diagram presented, it is possible to state that CFA is a strong chelator for $\mathrm{Eu}^{3+}$, between $\mathrm{pH} \approx 7$ and 10 , since almost all $\mathrm{Eu}^{3+}$ is complexed. Nevertheless, a meaningful evaluation can be only achieved if we compare the sequestering/chelating ability of CFA towards other trivalent metal cations, or the ability of similar ligands towards $\mathrm{Eu}^{3+}$. To the best of our knowledge, the only reliable data published considering the chelation of CFA with trivalent cations are in the work of Adams et al. [59], which reports a study of the solution equilibria between $\mathrm{Al}^{3+}$ and several 1,2-dihydroxyaryl ligands, including CFA, in aqueous solution, at $I=0.1 \mathrm{~mol} \cdot \mathrm{dm}^{-3} \mathrm{KCl}_{(\mathrm{aq})}$ and $T=298.15 \mathrm{~K}$. 
There is also a more recent study from Beneduci et al. [60], but performed at $T=310.15 \mathrm{~K}$. In contrast, due to the fast reduction of $\mathrm{Fe}^{3+}$ in aqueous solution in the presence of CFA, no data regarding $\mathrm{Fe}^{3+} / \mathrm{CFA}$ system were reported [61]. Concerning other ligands, it is worth comparing the chelation properties of CFA towards $\mathrm{Eu}^{3+}$ with those of the simple catechol system [62] and gallic acid (3,4,5-trihydroxybenzoic acid) [63] towards the same cation.

However, to compare different metal-ligand systems, the simple evaluation of the stability constants and/or the formation percentages of different metal-ligand complexes can be misleading, as we may have a different number and a different nature of complexes formed. In the different systems under comparison, we may have ligands with different denticities, different solution conditions, different acid-base properties, but also different metal cations. We may even have competition reactions between other metals and ligands simultaneously present, as protonation reactions and metal hydrolysis compete with the metal complex formation reactions [35,64-67].

To overcome these questions, several parameters have been proposed. One of these parameters is the $\mathrm{pM}$ value, commonly used in biological and medicinal chemistry to compare the affinity of different ligands for a specific metal under physiological conditions. This parameter is well-known and very often used for the comparison of the sequestering ability of different siderophores towards $\mathrm{Fe}^{3+}$ (being indicated as $\mathrm{pFe}$ in that particular case). pFe was defined by Raymond et al. in 1979 as $-\log \left[\mathrm{Fe}^{3+}\right],\left[\mathrm{Fe}^{3+}\right]$ being the concentration of the free aqueous ion $\left[\mathrm{Fe}\left(\mathrm{H}_{2} \mathrm{O}\right)_{6}\right]^{3+}$ present in the solution at specific experimental conditions $\left(\mathrm{pH}=7.4, c_{\mathrm{Fe}}=1 \mu \mathrm{mol} \cdot \mathrm{dm}^{-3}\right.$ and $\left.c_{\mathrm{L}}=10 \mu \mathrm{mol} \cdot \mathrm{dm}^{-3}\right)$ [68]. As such, the higher the $\mathrm{pM}$, the lower the concentration of free metal cation, and so, the better the chelation ability. In this work, based on the stability constants determined for our $\mathrm{Eu}^{3+} / \mathrm{CFA}$ system, we were able to determine the $\mathrm{pEu}$ parameter. This can be compared with the $\mathrm{pM}$ calculated for the other mentioned systems, using the stability constants reported (in particular, Eu $\mathrm{u}^{3+} / \mathrm{catechol}$ (CAT) [62], $\mathrm{Eu}^{3+} /$ gallic acid (GAL) [63], and $\mathrm{Al}^{3+} / \mathrm{CFA}$ [59]). The results are depicted in Figure 9.

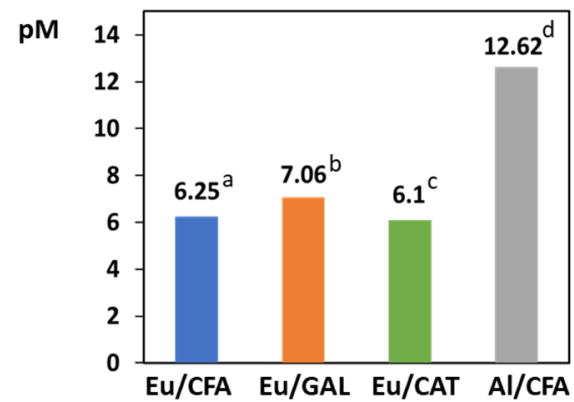

Figure 9. $\mathrm{pM}$ values calculated at $\mathrm{pH}=7.4, c_{\mathrm{M}}=1 \mu \mathrm{mol} \cdot \mathrm{dm}^{-3}$ and $c_{\mathrm{L}}=10 \mu \mathrm{mol} \cdot \mathrm{dm}^{-3}$, for several $\mathrm{M} /$ polyphenolic systems $\left(\mathrm{M}=\mathrm{Eu}^{3+}, \mathrm{Al}^{3+}\right)$, using data (a) determined in this work; reported in (b) [63]; (c) [62]; (d) [59].

The obtained $\mathrm{pM}$ values revealed a very similar chelating ability of the catecholatetype ligands towards $\mathrm{Eu}^{3+}$, with a slightly higher value for gallic acid. This result was expected considering that the coordination involved in all systems is very similar: the $\mathrm{Eu}^{3+}$ metal cation is coordinated by two adjacent hydroxyl groups from the aromatic ring (catecholate moiety). Considering the $\mathrm{pAl}$ calculated for the $\mathrm{Al}^{3+} / \mathrm{CFA}$ system, the absolute value is about double, which could appear as the result of better chelation ability of CFA towards $\mathrm{Al}^{3+}$. However, this result is just proof that $\mathrm{pM}$ value has to be used carefully. As already mentioned, $\mathrm{pM}$ value is determined by considering the concentration of the free metal cation in the solution, in specific conditions $\left(\mathrm{pH}=7.4, c_{\mathrm{M}}=1 \mu \mathrm{mol} \cdot \mathrm{dm}^{-3}\right.$ and $c_{\mathrm{L}}=10 \mu \mathrm{mol} \cdot \mathrm{dm}^{-3}$ ). In this sense, this parameter is particularly robust when used to compare the systems of very strong chelators towards the metals in the study (such as siderophores towards $\mathrm{Fe}^{3+}$, usually having $\log \beta>20$ ), as there are very few (if any) other reactions competing with the complex formation reaction. In that case, the metal 
that is "not free" is bound to the ligand (siderophore) and we can, for example, easily compare the sequestering ability of several siderophores towards $\mathrm{Fe}^{3+}$. Unfortunately, the strength and greatness of this parameter-mainly represented by the easy-to-understand concepts behind it and the easiness of its calculation, even by non-experts-resulted in a sort of boomerang effect due to frequent "deviations" from Raymond's original intentions and to its misuse, generating confusion in literature when conducting comparisons. For example, several $\mathrm{pM}$ values can be found in the literature for many systems, calculated in $\mathrm{pH}$ conditions and/or metal and ligand concentrations and ratios that significantly differ from each other, and from Raymond's original; further details may be found, for example, in references $[65,66])$. In particular, in systems where the metal cation-ligand coordination is not so strong, other reactions (such as the hydrolysis of the metal cation) compete with the metal sequestration process, resulting in the formation of hydroxo-species. This leads to a still low concentration of the free metal cation in the system (resulting in a high pM value), but to a non-realistic evaluation of the sequestering ability of the ligand itself, as most or part of the metal is not bound to it [65]. This is exactly what we observe in the $\mathrm{Al}^{3+} /$ CFA system: in the conditions of the $\mathrm{pM}$ calculation $\left(\mathrm{pH}=7.4, c_{\mathrm{Al}}=1 \mu \mathrm{mol} \cdot \mathrm{dm}^{-3}\right.$ and $\left.c_{\mathrm{L}}=10 \mu \mathrm{mol} \cdot \mathrm{dm}^{-3}\right)$, the concentration of free $\mathrm{Al}^{3+}$ is very low $\left(\approx 10^{-13} \mathrm{~mol} \cdot \mathrm{dm}^{-3}\right)$, which results in a high pM value; however, only $52 \%$ of $\mathrm{Al}^{3+}$ is bound to CFA, with $48 \%$ of $\mathrm{Al}^{3+}$ being present in the form of $\mathrm{Al}(\mathrm{OH})_{x}$ hydroxo-species.

To overcome this situation, a new parameter was defined by Sammartano and coworkers [67], called $\mathrm{pL}_{0.5}$. While $\mathrm{pM}$ is dependent on the concentration of the free metal, $\mathrm{pL}_{0.5}$ is determined on the basis of the concentration of the metal that is effectively bound to the ligand. In this way, it can be used for the comparison of systems with different speciation schemes; different ligands toward the same metal cation; the same ligand toward different cations; the same ligand/cation system under different conditions of $\mathrm{pH}$, temperature, and ionic strength; and in the presence of other cations and ligands undergoing many different competing equilibria [67]. $\mathrm{pL}_{0.5}$ is then an empirical parameter that represents the ligand concentration necessary to sequester $50 \%$ of the metal cation when the latter is present in trace amounts (see Equation (3)).

The $\mathrm{pL}_{0.5}$ was then determined for the $\mathrm{Eu}^{3+} / \mathrm{CFA}$ system, at different $\mathrm{pH}$ values, and the individual sequestration diagrams are represented in Figure 10a, while the corresponding $\mathrm{pL}_{0.5}$ values for the chosen comparative systems at $\mathrm{pH}=7.4$ are shown in Figure 10b. From the diagrams in Figure 10a we can observe that the sequestering ability of CFA towards $\mathrm{Eu}^{3+}$ increases with the rise of $\mathrm{pH}$, this growth being less remarkable at higher $\mathrm{pH}$ values. When compared with the same systems mentioned before, the behaviour between the different systems is very similar at $\mathrm{pH}=7.4$. In terms of absolute values, gallic acid (GAL) generally presents a higher sequestering ability for $\mathrm{Eu}^{3+}$ than the other two catecholate ligands (CFA and CAT), and CFA seems to be a good chelator for both $\mathrm{Eu}^{3+}$ and $\mathrm{Al}^{3+}$ at $\mathrm{pH}=7.4$.

(a)

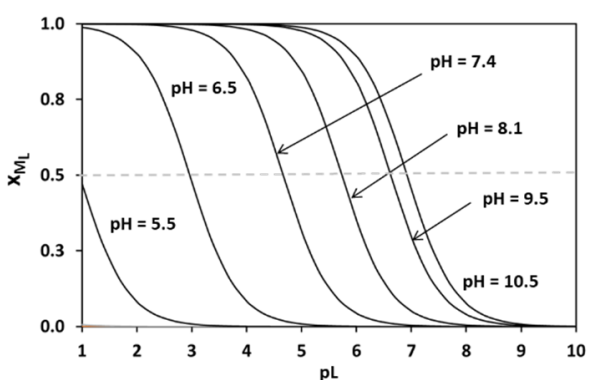

(b)

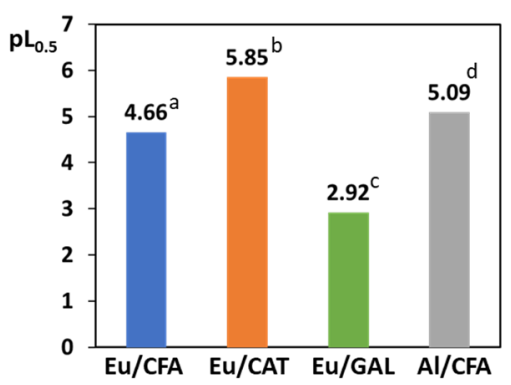

Figure 10. (a) Sequestration diagrams of $\mathrm{Eu}^{3+}$ by CFA at different $\mathrm{pH}$ values, at $I=0.2 \mathrm{~mol} \cdot \mathrm{dm}^{-3}$ in $\mathrm{KCl}_{(\mathrm{aq})}$, at $\mathrm{T}=298.15 \mathrm{~K}$. (b) $\mathrm{pL}_{0.5}$ values calculated at $\mathrm{pH}=7.4$ for several $\mathrm{M} /$ polyphenolic systems $\left(\mathrm{M}=\mathrm{Eu}^{3+}, \mathrm{Al}^{3+}\right)$ using data (a) determined in this work; reported in (b) [62]; (c) [63]; (d) [59]. 


\subsection{Biological Studies}

\subsubsection{Antimicrobial Activity}

The minimum inhibitory concentration (MIC) values for the studied compounds and reference substances $\left(\mathrm{EuCl}_{3}\right.$, gentamicin and fluconazole) are presented in Table 6. In general, Eu(III)-caffeinate showed higher antibacterial activity against Escherichia coli (Gram(-) bacteria) and Bacillus subtilis (Gram(+) bacteria) when compared with CFA and $\mathrm{EuCl}_{3}$ alone. This result is in agreement with the recently published review by Cota et al. [27], which reported that upon complexation with $\mathrm{Ln}^{3+}$ ions, the activity of the parent $\mathrm{L}$ is enhanced due to the increased lipophilicity, which allows $\mathrm{Ln}^{3+}$ complexes to penetrate through the lipid membranes of the cell and to cause a disturbance of the normal functioning of the cell, finally leading to cell death. This is usually explained by the Tweedy's chelation theory and Overtone's concept, which claims that cell permeability is highly dependent on the lipophilic character of their membrane, which favours the passage of only lipid soluble materials $[27,69,70]$. In our particular system we can assume an increase in lipophilicity after complexation, explained by the fact that the positive charge of the metal ion is partially shared with donor atoms, leading to a $\pi$-electron delocalization over the chelate ring [32,71].

Table 6. The minimum inhibitory concentration (MIC) values for tested compounds against selected microorganisms.

\begin{tabular}{|c|c|c|c|c|}
\hline \multirow[t]{2}{*}{ Microorganism } & \multicolumn{4}{|c|}{$\begin{array}{c}\text { MIC } \\
\mathrm{mg} \cdot \mathrm{cm}^{-3}\left(\mathrm{mmol} \cdot \mathrm{dm}^{-3}\right)\end{array}$} \\
\hline & CFA & Eu-Caffeinate & $\mathrm{EuCl}_{3}$ & Positive Control \\
\hline $\begin{array}{c}\text { Escherichia coli } \\
\text { Gram(-) } \\
\text { bacteria }\end{array}$ & $\begin{array}{c}13 \\
(72.2)\end{array}$ & $\begin{array}{c}4 \\
(5.1)\end{array}$ & $\begin{array}{c}10 \\
(27.3)\end{array}$ & $\begin{array}{c}\text { Gentamicin } \\
0.0005 \\
(0.001)\end{array}$ \\
\hline $\begin{array}{l}\text { Bacillus subtilis } \\
\operatorname{Gram}(+) \text { bacteria }\end{array}$ & $\begin{array}{c}18 \\
(99.9)\end{array}$ & $\begin{array}{c}4 \\
(5.1)\end{array}$ & $\begin{array}{c}12 \\
(32.8)\end{array}$ & $\begin{array}{c}\text { Gentamicin } \\
0.005 \\
(0.01)\end{array}$ \\
\hline $\begin{array}{l}\text { Candida albicans } \\
\text { (fungi) }\end{array}$ & $\begin{array}{c}29 \\
(161.0)\end{array}$ & $\begin{array}{c}>4 \\
(>5.1)\end{array}$ & $\begin{array}{c}6 \\
(16.4)\end{array}$ & $\begin{array}{c}\text { Fluconazole } \\
0.00025 \\
(0.00082)\end{array}$ \\
\hline
\end{tabular}

Notwithstanding, the interaction of metal and/or ligand functional groups with cellular components via different paths can also change the cell wall properties, resulting in a higher toxicity of metal complexes as compared to a free ligand [72].

We can also observe that CFA and Eu(III)-caffeinate seem to be less active against the studied fungus (Candida albicans) when compared with their action on $\operatorname{Gram}(-)$ and Gram(+) bacteria. This was already observed for other $\mathrm{Ln}^{3+}$ complexes and it is usually explained by the different composition of the fungus cell wall, which makes it more difficult to penetrate [27]. Interestingly, in the case of alkali metal-caffeinates (e.g., potassium caffeinate), we observe a slightly higher activity for Gram(+) and a much lower activity for $\operatorname{Gram}(-)$ bacteria and fungi [10].

\subsubsection{Microelectrophoretic Mobility Measurements}

As the interaction with the cellular membrane seems to be the main factor that explains the biological activity of CFA and its Eu(III) complexes, a detailed study was performed in order to obtain further insight into the compound-membrane interactions. This study was performed by electrophoretic mobility, a commonly used technique for surface characterization of nonbiological colloids and, more recently, bacterial, yeast or animal cells [73]. The determination of the surface charge of living cells $(\delta)$ is of prominent importance for understanding their behaviour and functions under various environmental conditions. The surface charge values of the E. coli, B. subtilis and C. albicans were measured as a function of $\mathrm{pH}$ in $0.2 \mathrm{~mol} \cdot \mathrm{dm}^{-3} \mathrm{KCl}_{(\mathrm{aq})}$ solutions, containing only $\mathrm{CFA}$ or $\mathrm{EuCl}_{3}$, and $\mathrm{EuCl}_{3}$ with CFA at a 1:1 metal to ligand molar ratio $\left(c=10^{-3} \mathrm{~mol} \cdot \mathrm{dm}^{-3}\right)$, as shown in Figure 11 . Briefly, 
E. coli and B. subtilis were net negatively charged at $\mathrm{pH}$ values above their isoelectric points in CFA, $\mathrm{Eu}(\mathrm{III})$ and $\mathrm{Eu}(\mathrm{III}) / \mathrm{CFA}$ systems. Furthermore, it is obvious that at low $\mathrm{pH}$ values, no statistically significant changes were observed in the $\delta$ of membranes of any bacterium placed in the tested solutions compared with the control group (bacterium in the $0.2 \mathrm{~mol} \cdot \mathrm{dm}^{-3} \mathrm{KCl}_{(\mathrm{aq})}$ only). The effect of the tested compounds on the $\delta$ values, due to their specific adsorption on the microbial membrane, becomes more significative as the $\mathrm{pH}$ increases. In our studies we observed a decrease in the negative surface charge, with the lowest values for: bacterium + CFA $<$ bacterium $+\mathrm{Eu}(\mathrm{III})<$ bacterium $+\mathrm{Eu}(\mathrm{III}) / \mathrm{CFA}$ (see Figure 11). Interestingly, in the case of measurements performed with C. albicans, we obtained positive surface charge values for low $\mathrm{pH}$ in the solutions containing Eu(III)/CFA, and at high $\mathrm{pH}$ values for the solutions containing only Eu(III). The different membrane response to the presence of the metal complex can explain the lower activity observed against C. albicans when compared with the tested bacteria, in the MIC assays previously described.
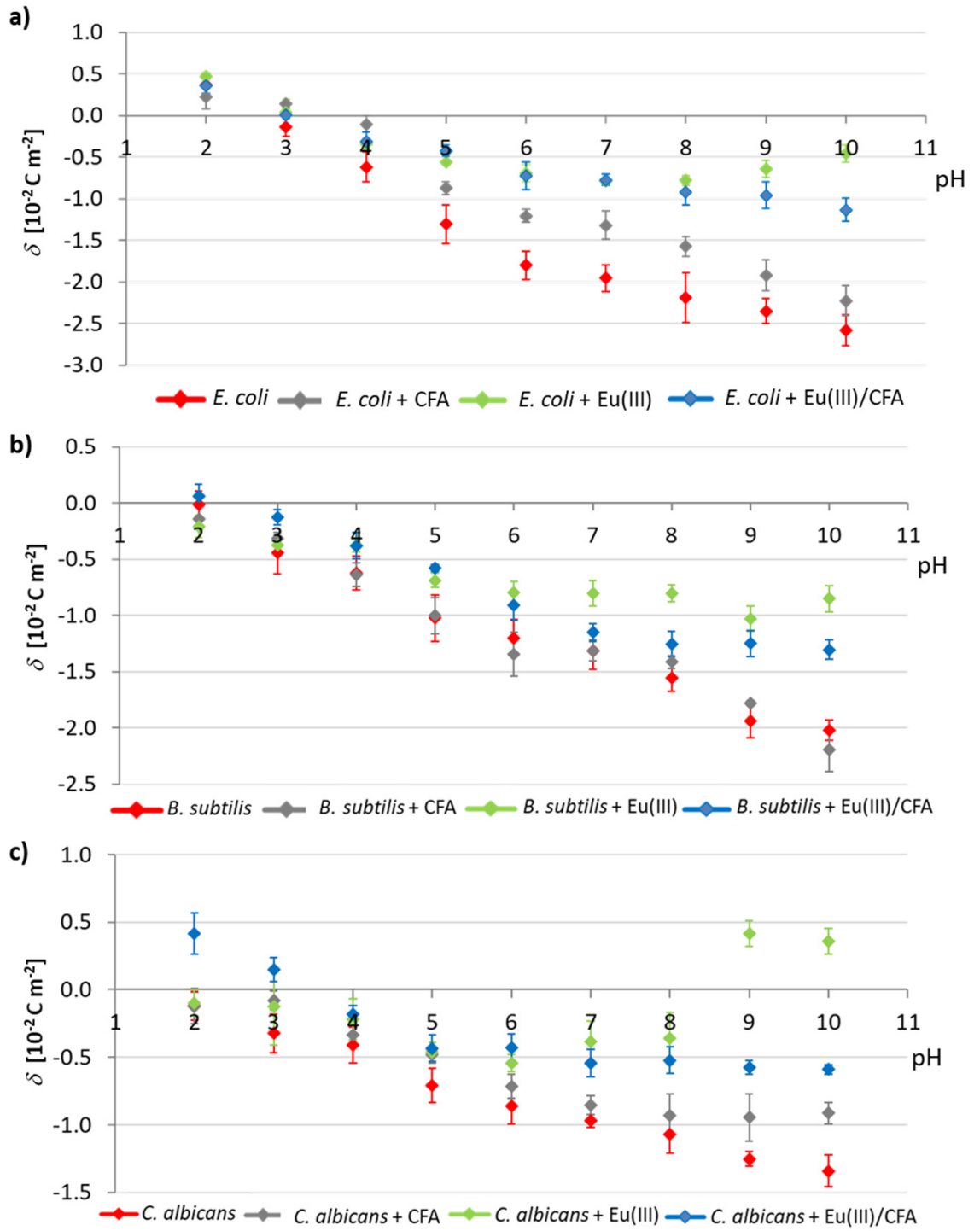

Figure 11. Influence of CFA, $\mathrm{Eu}(\mathrm{III})$ and $\mathrm{Eu}(\mathrm{III}) / \mathrm{CFA}$ system on the surface charge of: (a) E. coli, (b) $B$. subtilis and (c) C. albicans membranes.

Schott and Young [74] reported that polyvalent cations replace potassium and sodium ions originally bound to the carboxylate groups of the cell wall, and are firmly attached to these groups. Carboxylates coordinating di- and/or trivalent cations undergo little or no dissociation, as the formed bonds are stronger than in the case of $\mathrm{K}^{+}$or $\mathrm{Na}^{+}$coordination. 
This cation exchange process reduces the negative charge of the microbial membrane, which is consistent with our microelectrophoretic results. It is also reported that the metal binding on the microorganisms' surface is probably the initial step in the uptake and concentration of the metals by the microbes, and in the toxic effects of these metals [75]. Our study showed significant $\mathrm{pH}$-dependent changes in the surface charge values of microorganisms deposited on solutions containing $\mathrm{Eu}(\mathrm{III})$ and $\mathrm{Eu}(\mathrm{III}) / \mathrm{CFA}$, suggesting a dependence on the interaction of the membrane surface with the species in a solution, i.e., on the chemical speciation. Considering the Eu(III)/CFA system, and in agreement with the speciation diagram presented in Figure 8 , we can see that until $\mathrm{pH} \approx 6, \mathrm{Eu}(\mathrm{III})$ is free in a solution, and this explains the overlap of the measurements observed for the systems of microorganism/Eu(III) and microorganism/Eu(III)/CFA. At higher pH values, the coordination occurs, with the formation of a neutral [Eu(CFA)] species. Above pH 8-9, the formation of the negatively charged $[\mathrm{Eu}(\mathrm{CFA})(\mathrm{OH})]^{-}$species changes the interaction with the tested membranes, as can be seen in Figure 11. The same is observed for the $\mathrm{Eu}(\mathrm{III})$ metal cation, where the effect is even higher, maybe due to a higher charge density. The toxicity of some metals to microorganisms varies with $\mathrm{pH}$ due to the hydrolysed species of these metals, which occur at higher $\mathrm{pH}$ values, bind to the cell surface and alter the net charge of the cell. Such a change in charge could affect various physiological functions of the cell, as well as its interactions with other cells and constituents present in the environment [75]. When analysing the three systems together, we can point out some relevant differences observed in the $C$. albicans membranes, which can explain the lower toxicity observed on MIC assays. Moreover, the obtained results can be also an indication that the speciation form of the metal cation, which depends on the presence of, for example, CFA and $\mathrm{pH}$, rather than the type of microorganism, is a more relevant factor in determining changes in charge and membrane interactions, and hence, adsorption and toxicity.

\subsubsection{Antioxidant Activity}

Besides the toxicity of the new metal complexes, we also studied how the high antioxidative potential of CFA was affected by the coordination with Eu(III). As such, we performed five independent antioxidant assays that showed that Eu(III) did not affect the antioxidant activity of CFA, or even decrease it (Figure 12). CFA exhibited strong antiradical activity against DPPH• (the obtained $\mathrm{IC}_{50}=3.29 \pm 0.29 \mu \mathrm{mol} \cdot \mathrm{dm}^{-3}$ ) and ABTS $\bullet+$ $\left(\%\right.$ Inh. $\left.=85 \% ; c=50 \mu \mathrm{mol} \cdot \mathrm{dm}^{-3}\right)$, whereas $\mathrm{Eu}(\mathrm{III}) / \mathrm{CFA}$ exhibited no activity toward $\mathrm{DPPH} \bullet$ in the tested concentration; furthermore, the percentage inhibition of ABTS $\bullet$ was slightly lower than for acid alone (77\%). For Eu(III)-caffeinate, it was not possible to determine the $\mathrm{IC}_{50}$ in DPPH assay because it precipitated at a higher concentration. $\mathrm{Eu}(\mathrm{III})$ / caffeinate complex showed reducing properties in CUPRAC and FRAP tests, but less than CFA (CUPRAC assay: 285.08 and 343.99 Trolox equivalents; FRAP assay: 15.79 and $18.24 \mu \mathrm{mol} \cdot \mathrm{dm}^{-3}$ of $\mathrm{Fe}^{2+}$ for Eu(III)-caffeinate and the CFA complex and CFA, respectively). With the increase in the concentration of $\mathrm{Eu}(\mathrm{III})$-caffeinate, its antioxidant activity increases as well. Studied compounds inhibited the peroxidation of lipids (in the test with linoleic acid). Until the third day, the differences between the compounds and their different concentrations were slight, but after the fifth day of measurement, Eu(III)-caffeinate at a higher concentration still possessed the antioxidant activity ( $\%$ Inh. $\approx 43 \%$ ), similarly to CFA (\%Inh. $\approx 45 \%)$.

The antioxidant activity of phenolic acids is determined by the presence of the hydroxyl group $(-\mathrm{OH})$ in the aromatic ring. The phenols with more than one $-\mathrm{OH}$ located in an ortho-position to each other, such as CFA, revealed the strongest antioxidant activity [76]. 
(a)

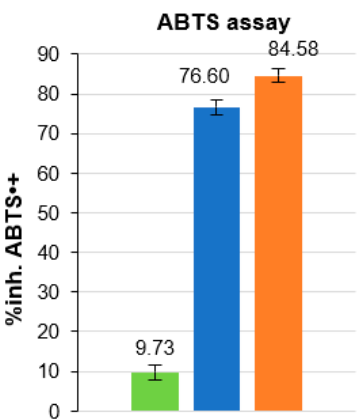

(b)

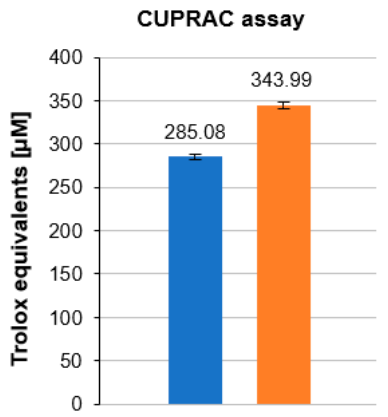

(c)

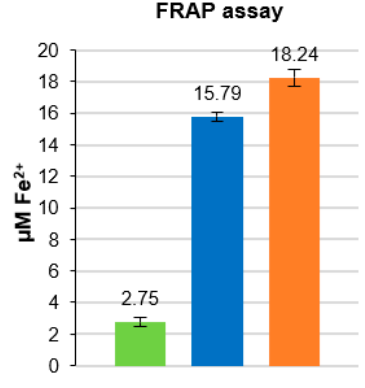

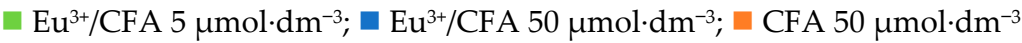

(d)

\section{Inhibition of lipid peroxidation}

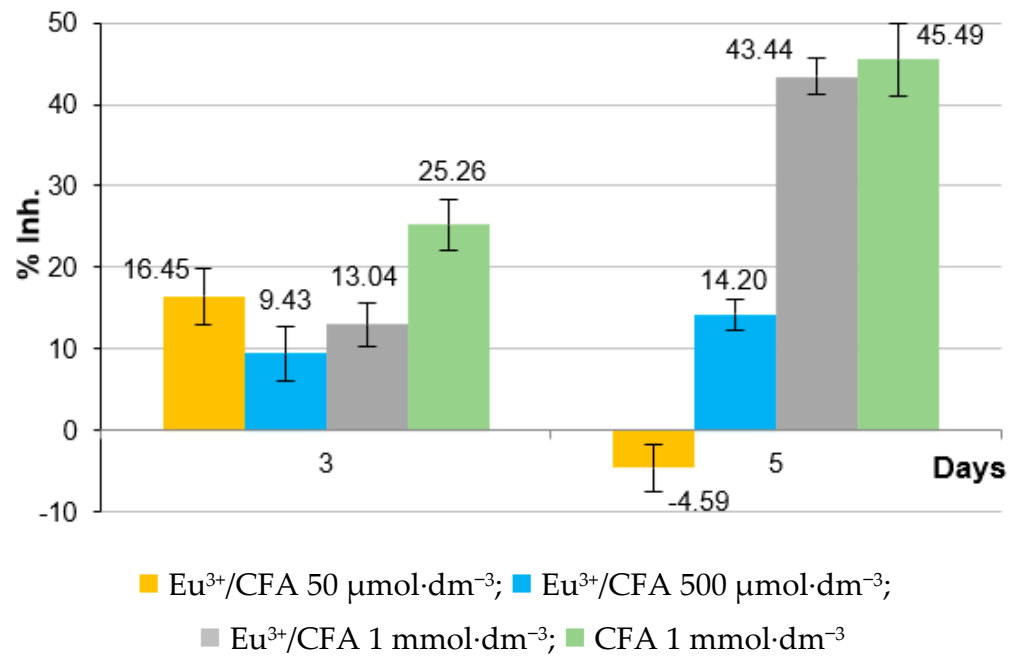

Figure 12. Antioxidant activity assays of CFA and Eu-CFA at indicated concentrations: (a) percentage of inhibition of $\mathrm{ABTS}^{\bullet+}$ cation radicals; (b) results of CUPRAC assays expressed as Trolox equivalents [ $\left.\mu \mathrm{mol} \cdot \mathrm{dm}^{-3}\right]$; (c) evaluation of the reducing ability by FRAP assay; (d) percentage of inhibition of lipid peroxidation by $\mathrm{Eu}^{3+} / \mathrm{CFA}$ complex at the concentrations of 50,500 and $1000 \mu \mathrm{mol} \mathrm{dm}{ }^{-3}$. Mean values from three independent experiments $\pm \mathrm{SD}$ are shown.

This is attributed to the lower energy of the $\mathrm{O}-\mathrm{H}$ bond dissociation (BDE) that facilitates the donation of a hydrogen and/or an electron from the hydroxyl group to the reactive species (basicity). The antioxidant assays are generally based on electron (single electron transfer, SET) or hydrogen transfer (hydrogen atom transfer, HAT) or mixed mechanisms: sequential proton loss-electron transfer (SPLET) or single electron transferproton transfer (SET-PT) [77]. In DPPH• and ABTS •+ assays, antioxidants can react with radicals by a combination of SET and HAT mechanisms (i.e., the SPLET mechanism), whereas FRAP and CUPRAC assays are based on the SET mechanism [78]. Moreover, it was reported that SPLET is the most favourable mechanism of action in a polar solvent, while HAT dominates in a non-polar solvent (e.g., benzene) [79]. The $\mathrm{pH}$ of the medium may also affect the final results of the antioxidant assays. The CUPRAC test was conducted at $\mathrm{pH} \approx 7$ whereas the other assays were carried out at a lower $\mathrm{pH}$. As is shown in our studies in a solution (Figure 8), at a $\mathrm{pH}<6$ the ligand remains almost uncoordinated, which causes the small difference in the results obtained for the complex and the ligand in FRAP, ABTS and lipid peroxidation assays. 


\section{Materials and Methods}

\subsection{Chemicals}

Caffeic acid (3-(3,4-Dihydroxyphenyl)-2-propenoic acid, CFA), europium(III) chloride hexahydrate $\left(\mathrm{EuCl}_{3} \cdot 6 \mathrm{H}_{2} \mathrm{O}\right)$, DPPH (2,2-diphenyl-1-picrylhydrazyl), ABTS (2,2-azinobis(3-ethylbenzothiazoline-6-sulfonic acid), potassium persulfate $\left(\mathrm{K}_{2} \mathrm{~S}_{2} \mathrm{O}_{8}\right)$, TPZT $(2,4,6$ tris(2-pyridil)-s-triazine), iron(III) chloride hexahydrate $\left(\mathrm{FeCl}_{3} \cdot 6 \mathrm{H}_{2} \mathrm{O}\right)$, sodium acetate $\left(\mathrm{C}_{2} \mathrm{H}_{3} \mathrm{NaO}_{2} \cdot 3 \mathrm{H}_{2} \mathrm{O}\right)$, copper(II) chloride $\left(\mathrm{CuCl}_{2}\right)$, ammonium acetate $\left(\mathrm{CH}_{3} \mathrm{COONH}_{4}\right)$, neocuproine (2,9-dimethyl-1,10-phenanthroline), iron(II) sulfate $\left(\mathrm{FeSO}_{4}\right)$, Trolox (6-hydroxy2,5,7,8-tetramethylchroman-2-carboxylic acid), hydrogen peroxide $\left(\mathrm{H}_{2} \mathrm{O}_{2}\right)$, gentamycin and fluconazole were purchased from Sigma-Aldrich Co. (St. Louis, MO, USA). Potassium hydroxide $(\mathrm{KOH})$ and hydrochloric acid $(\mathrm{HCl})$ TitraFix ${ }^{\mathrm{TM}}$ were purchased from POCH S.A. (Gliwice, Poland). $\mathrm{KOH}$ and $\mathrm{HCl}$ solutions were prepared by diluting the concentrated ampoules and were standardized against potassium hydrogen phthalate (Standard Reference Material, Merck, Germany) and tris (hydroxymethyl) aminomethane (Tris, ACS reagent, $\geq 99.8 \%$, Sigma-Aldrich, St. Louis, MO, USA), respectively. Mueller-Hinton agar was supplied by Oxoid (Hampshire, UK). Methanol was sourced from Merck (Darmstadt, Germany). All chemicals had an analytical purity and were used without further purification. Ultrapure water was taken from a Milli-Q water (Millipore Direct-Q 3, Merck)

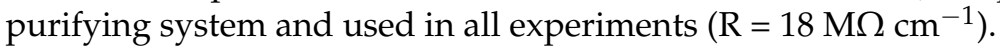

\subsection{Synthesis and Characterization of Eu(III) Metal Complexes}

A quantity of CFA in the amount of $0.003 \mathrm{~mol}$ was dissolved in a $0.1 \mathrm{~mol} \cdot \mathrm{dm}^{-3}$ aqueous solution of $\mathrm{NaOH}$ in a stoichiometric ratio of 1:1. The dissolution process was supported in an ultrasonic bath at $T=323.15 \mathrm{~K}$. A clear solution of sodium caffeinate was obtained, to which an aqueous solution of $\mathrm{EuCl}_{3}$ with a concentration of $0.01 \mathrm{~mol} \cdot \mathrm{dm}^{-3}$ in a stoichiometric ratio of 3:1 (sodium caffeinate: europium chloride) was slowly added.

The resulting mixture was stirred at room temperature for $2 \mathrm{~h}$ and the mixture was then left for $48 \mathrm{~h}$. The precipitated solid was filtered and washed with deionized water. The obtained complex was dried at $T=303.15 \mathrm{~K}$ for 3 days. For comparative reasons, the complexes of europium with cinnamic and $p$-coumaric acid were prepared following the same procedure.

Elemental composition of the prepared complexes was determined using a CHN 2400 PerkinElmer Analyzer. The following results were obtained: for europium caffeinate complex, $\mathrm{Eu}\left(\mathrm{C}_{9} \mathrm{H}_{7} \mathrm{O}_{4}\right)_{3} \cdot 5 \mathrm{H}_{2} \mathrm{O}: \mathrm{C}_{\text {exp }}=40.30 \%\left(\mathrm{C}_{\text {calc }}=41.60 \%\right), \mathrm{H}_{\text {exp }}=3.65 \%\left(\mathrm{H}_{\text {calc }}=4.01 \%\right)$; for europium cinnamate, $\mathrm{Eu}\left(\mathrm{C}_{9} \mathrm{H}_{5} \mathrm{O}_{2}\right)_{3} \cdot 6 \mathrm{H}_{2} \mathrm{O}: \mathrm{C}_{\exp }=47.40 \%\left(\mathrm{C}_{\text {calc }}=47.04 \%\right), \mathrm{H}_{\text {exp }}=3.26 \%$ $\left(\mathrm{H}_{\text {calc }}=3.07 \%\right)$; for europium $p$-coumarate, $\mathrm{Eu}\left(\mathrm{C}_{9} \mathrm{H}_{6} \mathrm{O}_{3}\right)_{3} \cdot 4 \mathrm{H}_{2} \mathrm{O}: \mathrm{C}_{\exp }=45.78 \%\left(\mathrm{C}_{\text {calc }}=45.97 \%\right)$, $\mathrm{H}_{\text {exp }}=2.85 \%\left(\mathrm{H}_{\text {calc }}=3.00 \%\right)$. The europium caffeinate was also analysed using thermal analysis (TGA) using a Setsys 16/18 (Setaram). The resulting elemental formula of the complexes is: $\left[\mathrm{Eu}(\mathrm{CFA})_{3}\left(\mathrm{H}_{2} \mathrm{O}\right)_{3}\right] \cdot 2 \mathrm{H}_{2} \mathrm{O}$.

The structure of the metal complex of caffeic, cinnamic and $p$-coumaric acids, with europium, is described on the basis of spectroscopic studies, complemented with literature and X-ray data reported in the CSD crystallographic database. Infrared (IR) and Raman spectra (KBr and ATR techniques) were recorded with an Alfa spectrophotometer and a MultiRam, respectively, both from Bruker (Berlin, Germany).

\subsection{Potentiometric Measurements}

An Orion Star ${ }^{\mathrm{TM}} \mathrm{T} 900$ Series Potentiometric Titrator (Thermo Scientific ${ }^{\mathrm{TM}}$, Waltham, MA, USA) equipped with an automatic burette and a combined glass electrodeOrion ${ }^{\mathrm{TM}}$ 8102BNUWP ROSS Ultra ${ }^{\mathrm{TM}}$ or Orion ${ }^{\mathrm{TM}}$ 8103BNUWP ROSS UltraTM (Thermo Scientific ${ }^{\mathrm{TM}}$ ) was used for potentiometric titrations (estimated accuracy $\pm 0.2 \mathrm{mV}$ and $0.002 \mathrm{~cm}^{3}$ for the electromotive force reading and titrant additions, respectively). The potentiometric titrations were carried out using a double-walled glass cell connected to a water circulator as titration vessel. All titrations were conducted in an argon atmosphere, at the constant 
ionic strength of $I=0.2 \mathrm{~mol} \cdot \mathrm{dm}^{-3} \mathrm{KCl}_{(\mathrm{aq})}$ and at $T=298.15 \pm 0.1 \mathrm{~K}$, in a $\mathrm{pH}$ range between $\approx 2$ and 11 (or until observation of precipitation formation), using $\mathrm{CO}_{2}$-free $\mathrm{KOH}$ as a titrant.

The combined glass electrode was calibrated prior to each titration to determine the value of electrode potential $\left(E^{0}\right)$ and water dissociation constant $\left(\mathrm{p} K_{\mathrm{w}}\right)$. The calibration was carried out using a strong acid-strong base titration with no metal ion and ligand addition, in the presence of a background electrolyte in the same experimental conditions of ionic medium, strength and temperature $\left(I=0.2 \mathrm{~mol} \cdot \mathrm{dm}^{-3}\right.$ in $\left.\mathrm{KCl}_{(\mathrm{aq})}, T=298.15 \pm 0.1 \mathrm{~K}\right)$. The total volume of the titration solution was $30.0 \mathrm{~cm}^{3}$ and the $\mathrm{KOH}$ solution was added in small increments to provide about 100 experimental data points for each run. The calibrations were performed in terms of free proton concentration (i.e., $\mathrm{pH}=-\log \left[\mathrm{H}^{+}\right]$, not activity), as previously described $[36,64,65]$. For the investigation of the acid-base properties of the ligand, several solutions containing different concentrations of CFA $\left(c_{\mathrm{L}} \approx 1.0 \mathrm{mmol} \cdot \mathrm{dm}^{-3}\right)$, known amounts of $\mathrm{HCl}$ to lower $\mathrm{pH}$, and $\mathrm{KCl}$ were titrated with standardized $\mathrm{KOH}$ solutions. The same procedure was used for the study of metal-ligand interactions: several titrations were performed on solutions prepared as described above, plus suitable known amounts of $\mathrm{Eu}^{3+}$ to obtain different metal to ligand ratios $\left(1: 1 \leq c_{\mathrm{Eu}}: c_{\mathrm{L}} \leq 1: 3\right)$. Especially for experiments performed in the presence of metal cation, several trials were carried out to verify the reaching of equilibrium conditions, by checking and testing various equilibration times (up to several hours) and performing back-titrations.

\subsection{UV-Vis Spectrophotometric Measurements}

All UV-Vis spectrophotometric titrations were carried out using a Hitachi UV-Vis H3600U Spectrophotometer. Spectra were registered in the wavelength range of 210-500 nm. The measurements were performed in the same conditions as the potentiometric experiments (constant temperature of $T=298.15 \pm 0.1 \mathrm{~K}$, maintained by the use of a coupled water circulator, and at $I=0.2 \mathrm{~mol} \cdot \mathrm{dm}^{-3}$ in $\left.\mathrm{KCl}_{(\mathrm{aq})}\right)$. Spectrophotometric measurements were carried out directly in quartz cuvettes by titrating $2.5 \mathrm{~cm}^{3}$ of the titrant solution with standard $\mathrm{KOH}$ solution, up to $\mathrm{pH} \approx 11$. The $\mathrm{pH}$ of each solution was measured using a combined glass electrode Orion ${ }^{\mathrm{TM}}$ 8103BNUWP ROSS Ultra ${ }^{\mathrm{TM}}$, calibrated as previously described. For the evaluation of the formation of metal cation-ligand species and the determination of the corresponding stability constants, several measurements were carried out using $\mathrm{CFA}$ and $\mathrm{EuCl}_{3}$ solutions at different metal to ligand ratios $\left(1: 1 \leq \mathcal{C}_{\mathrm{Eu}}: c_{\mathrm{L}} \leq 1: 3\right)$ and different concentrations $\left(c_{\mathrm{L}} \approx 10^{-5} \mathrm{~mol} \cdot \mathrm{dm}^{-3}\right)$.

\subsection{H-NMR Measurements}

${ }^{1} \mathrm{H}-\mathrm{NMR}$ experiments were performed using a Bruker Avance II 400 spectrometer. All the ${ }^{1} \mathrm{H}-\mathrm{NMR}$ experiments were carried out in solutions with a known ligand concentration of $c_{\mathrm{L}} \approx 10^{-3} \mathrm{~mol} \cdot \mathrm{dm}^{-3}$, in $\mathrm{KCl}_{(\mathrm{aq})}$ at $I=0.2 \mathrm{~mol} \cdot \mathrm{dm}^{-3}$ and at $T=293.15 \mathrm{~K}$, in $5 \mathrm{~mm} \mathrm{NMR}$ tubes. A $\mathrm{D}_{2} \mathrm{O}$ capillary was introduced in each NMR tube as external reference. The use of a $\mathrm{D}_{2} \mathrm{O}$ capillary, instead of the preparation of the samples on a $\mathrm{H}_{2} \mathrm{O} / \mathrm{D}_{2} \mathrm{O}$ mixture, avoids the need for evaluation of the isotopic effect, as the binding affinities of protonating groups are, in general, different for $\mathrm{D}^{+}$and $\mathrm{H}^{+}$[80]. Furthermore, a presaturation pulse sequence technique was used for water signal suppression. $\mathrm{KOH}$ standardized solution was used to adjust $\mathrm{pH}$, measured using a calibrated combined Orion ${ }^{\mathrm{TM}}$ 8103BNUWP ROSS Ultra ${ }^{\mathrm{TM}}$ semi-micro tipped glass combination electrode.

\subsection{ESI-MS Measurements}

Electrospray-ionization mass spectrometry (ESI-MS) studies of Eu(III)/CFA system were carried out using a Shimadzu LC MS/MS 8040 spectrometer under the following conditions: mobile phase: $95 \% \mathrm{MeOH}+5 \% \mathrm{HCOOH}\left(0.3 \%\right.$ in $\left.\mathrm{H}_{2} \mathrm{O}\right)$, flow rate: $0.3 \mathrm{~cm}^{-3} \cdot \mathrm{min}^{-1}$, injection volume: $1 \mu \mathrm{dm}^{3}$. Spectra were acquired in both positive and negative ion mode. The experiments were performed for solutions containing CFA alone and with $\mathrm{EuCl}_{3}$ at different metal to ligand molar ratios $\left(1: 1 \leq c_{\mathrm{Eu}}: c_{\mathrm{L}} \leq 1: 3\right)$, at $c_{\mathrm{L}} \approx 10^{-4} \mathrm{~mol} \cdot \mathrm{dm}^{-3}$. Samples were freshly prepared and injected immediately after preparation. 


\subsection{Thermodynamic Calculations}

Potentiometric titrations were processed using the non-linear least squares BSTAC4 computer program [81], which was used to determine the parameters $\left(\mathrm{p} K_{\mathrm{w}}, E^{0}\right.$, acidic junction potential coefficient $j_{\mathrm{a}}$, analytical concentrations of reagents) of the electrode calibrations, the protonation constants of CFA, and the stability constants of its $\mathrm{Eu}(\mathrm{III})$ complexes. Spectrophotometric data were analysed by the HypSpec2014 program [50], which allowed the determination of the stability constants and the molar absorbance spectra of each absorbing species. From the same suite of programs, HypNMR was used to evaluate ${ }^{1} \mathrm{H}-\mathrm{NMR}$ data [51]. The HYSS [82] and ES4 [81] programs were used to draw the speciation and the sequestration diagrams.

The stability constants of Eu(III)/CFA complexes are expressed considering the overall equilibrium according to Equation (1):

$$
p \mathrm{Eu}^{3+}+q \mathrm{~L}^{3-}+r \mathrm{H}^{+}=\mathrm{Eu}_{p} \mathrm{~L}_{q} \mathrm{H}_{r}^{(3 p-3 q+r)} \quad \log \beta_{p q r}
$$

The same equation is valid for the ligand protonation $(p=0)$ or $\mathrm{Eu}(\mathrm{III})$ hydrolysis constants $(q=0$ and $r<0)$. Protonation constants are also expressed as stepwise equilibria according to Equation (2):

$$
\mathrm{H}^{+}+\mathrm{LH}_{r-1}^{(r-4)}=\mathrm{LH}_{r}^{(r-3)} \quad \log \mathrm{K}_{0 q r}
$$

Formation constants, concentrations and ionic strengths are expressed in the molar concentration scale $\left(c, \mathrm{~mol} \cdot \mathrm{dm}^{-3}\right)$, and uncertainties are presented as \pm standard deviation (SD). When not relevant, and for simplicity, the charges of the various species are omitted.

Evaluation of the Sequestering Ability

The evaluation of the sequestering ability of CFA (and other compared ligands) towards $\mathrm{Eu}^{3+}$ (and other cations) has been performed by the calculation of a semi-empirical parameter, $\mathrm{pL}_{0.5}$; this represents the total concentration of the ligand $\left(\mathrm{L}\right.$, as $\left.-\log c_{\mathrm{L}}\right)$ necessary to bind $50 \%$ (as mole fraction, $x_{\mathrm{ML}}=0.5$ ) of a given component $(\mathrm{M}$, in this case, $\mathrm{Eu}^{3+}$ ) in a given solution when $\mathrm{M}$ is present as trace (in our case, for calculation purposes, $c_{\mathrm{M}}=10^{-24} \mathrm{~mol} \cdot \mathrm{dm}^{-3}$ ). Representing as $x_{\mathrm{ML}}$ the fraction of metal bound only to L vs. $-\log c_{\mathrm{L}}$, we obtain a sigmoidal curve (sequestration diagram) that can be fitted to Equation (3), a Boltzmann-type equation, where $\mathrm{pL}=-\log c_{\mathrm{L}}$, and $\mathrm{pL}_{0.5}$ is the only adjustable parameter.

$$
x_{\mathrm{M}_{\mathrm{L}}}=\frac{1}{1+10^{\left(\mathrm{pL}-\mathrm{pL}_{0.5}\right)}}
$$

From a quantification point of view, the higher the $\mathrm{pL}_{0.5}$, the greater the sequestering ability. Further details about this parameter, its genesis and meaning, the procedure to calculate it, and all the necessary equations are thoroughly described in reference [67]. Here, it is sufficient to mention that $x_{\mathrm{ML}}$ can be calculated by the mass-balance equation of the considered metal $(\mathrm{M})$ :

$$
c_{\mathrm{M}}=[\mathrm{M}]+\underbrace{\sum \mathrm{M}_{p}(\mathrm{OH})_{r}+\sum \mathrm{M}_{p^{\prime}} \mathrm{L}_{q^{\prime}}^{\prime} \mathrm{H}_{r^{\prime}}}_{\mathrm{M}_{\mathrm{L}^{\prime}}}+\underbrace{\sum \mathrm{M}_{p^{\prime \prime}} \mathrm{L}_{q^{\prime \prime}} \mathrm{H}_{r^{\prime \prime}}}_{\mathrm{M}_{\mathrm{L}}}+
$$

in which $c_{\mathrm{M}}$ is the total (analytical) concentration of the considered metal cation $\mathrm{M},[\mathrm{M}]$ is its free concentration, $\mathrm{M}_{\mathrm{L}}$ represent the summation of the concentrations of all the species formed by the cation $\mathrm{M}$ with the desired ligand $\mathrm{L}$, and $\mathrm{M}_{\mathrm{L}^{\prime}}$ stands for the concentration of all other species (including hydrolytic ones) formed by $\mathrm{M}$ with any other component and/or ligand different from L. Accordingly, $x_{\mathrm{ML}}$ is given by:

$$
x_{\mathrm{M}_{\mathrm{L}}}=\frac{c_{\mathrm{M}}-[\mathrm{M}]-\mathrm{M}_{\mathrm{L}^{\prime}}}{c_{\mathrm{M}}}
$$


In the way it is calculated, $\mathrm{pL}_{0.5}$ represents the effective sequestering ability of the specific ligand L, "cleaned" of all competing reactions, and can thus be calculated in systems of all possible complexities, in which many other cations and ligands can be simultaneously present with those of interest (e.g., multicomponent real systems such as natural waters and biological fluids). Furthermore, with the sequestering ability being dependent on the conditions of the system under investigation (e.g., $\mathrm{pH}$, ionic strength, temperature), so $\mathrm{pL}_{0.5}$ is. Of course, $x_{\mathrm{ML}}$ and, in turn, $\mathrm{pL}_{0.5}$ also depend on the analytical concentration of the metal (i.e., $c_{M}$ ). However, as soon as $c_{M}$ tends to 0 (i.e., at very low concentrations, such as those used in our calculations), $\mathrm{pL}_{0.5}$ usually tends to become a constant, and can be used for comparative purposes. In fact, despite Equation (3) not being fully rigorous and empirically derived from the sequestration diagrams, it proved excellent to model, in terms of sequestering ability, the behaviour of many systems of various complexity. Some other features of $\mathrm{pL}_{0.5}$, particularly in relation to similarities and differences with other approaches adopted for the same purposes, are discussed, for example, in reference [64-67].

\subsection{Antimicrobial Studies}

The MIC (Minimum Inhibitory Concentration) assay was determined by serial dilution of the test compound in an agar medium to which the appropriate inoculum of microorganisms was then added and incubated. The microorganisms used in the study came from the Polish Collection of Microorganisms (Wroclaw, Poland): E. coli (PCM 2857), B. subtilis (PCM 2850) and C. albicans (PCM 2566-FY). Microorganisms were grown overnight and then re-suspended in physiological solution to an optical density of 0.60 at $\lambda=600 \mathrm{~nm}(\mathrm{OD} 600)$, corresponding to $5.0 \times 10^{8} \mathrm{CFU} \cdot \mathrm{cm}^{-3}$ [50]. Microorganisms $\left(0.1 \mathrm{~cm}^{3}\right.$ of the reconstituted suspension) were seeded onto sterile Mueller-Hinton agar (containing $2 \%$ glucose) plates, to which previously suitable amounts of the tested compounds were added to give the desired concentration $\left(0.01-35.0 \mathrm{mg} \cdot \mathrm{cm}^{-3}\right.$, solutions were prepared from the synthesized Eu(III)-CFA complex). Tested chemicals were dissolved in dimethyl sulfoxide (DMSO) solution. Negative controls were agar plates to which DMSO was added, and positive control were plates with gentamicin (in the case of bacteria) or fluconazole (in the case of fungi). The standards were tested in the range of concentrations from $0.25-6.00 \mathrm{mg} \cdot \mathrm{dm}^{-3}$ in the case of gentamicin, and $0.10-1.09 \mathrm{mg}^{-\mathrm{dm}^{-3}}$ for fluconazole. The plates were incubated at $T=347.15 \mathrm{~K}$ for $24 \mathrm{~h}$. The lowest concentration without visible bacterial growth was determined as MIC.

\subsection{Microelectrophoretic Mobility Measurements}

E. coli (PCM 2857), B. subtilis (PCM 2850) and C. albicans (PCM 2566-FY) were harvested from the agar culture by centrifugation $(14,000 \mathrm{rpm}, 20 \mathrm{~min})$ and washed five times with background solution $\left(0.2 \mathrm{~mol} \cdot \mathrm{dm}^{-3} \mathrm{KCl}_{(\mathrm{aq})}\right)$ to remove any medium residues and to clean the microorganism suspensions before future analysis. The washed microorganisms were then suspended in the tested solutions to yield a final concentration of $2.5 \times 10^{7}$ microorganisms $\cdot \mathrm{cm}^{-3}$ and allowed to interact with the solution components for $1 \mathrm{~h}$ at room temperature. The tested solutions were $0.2 \mathrm{~mol} \cdot \mathrm{dm}^{-3} \mathrm{KCl}_{(\mathrm{aq})}$ solutions containing $\mathrm{CFA}, \mathrm{EuCl}_{3}$ or $\mathrm{EuCl}_{3}$ with $\mathrm{CFA}$ at 1:1 metal to ligand molar ratio, at $c \approx 10^{-3} \mathrm{~mol} \cdot \mathrm{dm}^{-3}$.

The electrophoretic mobility of the microbial cells was measured as a function of $\mathrm{pH}$ by a zeta potential analyser at $150 \mathrm{~V}$ (Zetasizer Nano ZS; Malvern Instruments Ltd., Malvern, UK) before being converted to surface charge density $(\delta)$ using the Equation (4), where $\mu$ is the electrophoretic mobility, $\eta$ is the solution viscosity, and $d$ is the diffuse layer thickness, previously determined using Equation (5) where $R$ is the gas constant, $T$ the experimental temperature, $F$ is the Faraday constant, $I$ is the ionic strength $\left(0.2 \mathrm{~mol} \cdot \mathrm{dm}^{-3}\right.$ in $\left.\mathrm{KCl}_{(\mathrm{aq})}\right)$, and $\varepsilon$ and $\varepsilon_{0}$ refer to the permittivity of free space and the relative permittivity of the medium [83].

$$
\delta=\frac{\eta \cdot \mu}{d}
$$




$$
d=\sqrt{\frac{\varepsilon \cdot \varepsilon_{0} \cdot R \cdot T}{2 \cdot F^{2} \cdot I}}
$$

Both bacteria and fungi suspended in tested solution were titrated to the desired $\mathrm{pH}$ (range 2-10) using $\mathrm{KOH}$ at the same ionic concentration as the cell suspension. Six electrophoretic mobility measurements were made (each covering 100-200 runs with a duration of $2 \mathrm{~s}$ ) for each $\mathrm{pH}$ value per sample. Each sample was measured in triplicate and values were presented as mean $\pm \mathrm{SD}$.

The sample cell used was the Malvern "Folded Capillary cell (DTS 1070)" of polyethylene, with $1 \mathrm{~cm}$ of optical length and coupled with electrodes. Aliquots of each cell suspension $\left(1 \mathrm{~cm}^{3}\right)$ were transferred to a Folded Capillary cell and the measurement was applied. Between each measurement, electrodes were rinsed with copious amounts of ethanol and Milli-Q water, followed by the tested microorganism suspension.

\subsection{Anti-Oxidative Studies}

All antioxidant assays were performed with samples prepared from the dissolution of the synthesized Eu(III)-CFA complex. All antioxidant assays were conducted in five repetitions for three independent experiments, and values were expressed as mean \pm SD.

\subsubsection{DPPH Assay}

The DPPH assay was conducted according to the Rice-Evans method described in reference [84]. Appropriate volumes of methanolic solutions of the tested compounds $\left(c=30 \mu \mathrm{mol} \cdot \mathrm{dm}^{-3}\right)$ were diluted in methanol in test tubes in order to prepare a series of solutions with various concentrations (final volume $1 \mathrm{~cm}^{3}$ ). Then, $2 \mathrm{~cm}^{3}$ of methanolic solution of DPPH• $\left(c=60 \mu \mathrm{mol} \cdot \mathrm{dm}^{-3}\right)$ was added to each tube. As a control, the same amount of DPPH• solution was added to a tube containing only methanol. After sample incubation for $60 \mathrm{~min}$, at $T=296.15 \mathrm{~K}$, in the dark, the absorbance at $\lambda=516 \mathrm{~nm}$ of the samples was measured on a Cary 5000 spectrophotometer (Varian, Santa Clara, CA, USA), against pure methanol. The ability to scavenge DPPH• radicals (\% Inh) was calculated according to Equation (6):

$$
\% \text { Inh }=\left[\left(A_{\text {control }}-A_{\text {sample }}\right) / A_{\text {control }}\right] \times 100 \%
$$

where: \% Inh is the percentage inhibition of DPPH• radical, $A_{\text {control }}$ is the absorbance of the control and $A_{\text {sample }}$ represents the absorbance of the tested sample. The concentration was plotted against the percentage Inh and the $\mathrm{IC}_{50}$ value (concentration of compound (antioxidant) that inhibited $50 \%$ of DPPH• radical) was calculated from the obtained scavenging curves.

\subsubsection{ABTS Assay}

The ABTS assay was performed as previously described [84]. The reagent was prepared by mixing aqueous solutions of ABTS $\left(c=7 \mathrm{mmol} \cdot \mathrm{dm}^{-3}\right)$ and $\mathrm{K}_{2} \mathrm{~S}_{2} \mathrm{O}_{8}\left(c=2.45 \mathrm{mmol} \cdot \mathrm{dm}^{-3}\right)$ in a volumetric ratio of $1: 1$, and left for $12-16 \mathrm{~h}$ at $T=296.15 \mathrm{~K}$ to generate ABTS $\bullet+$ cation radicals. Then, $1 \mathrm{~cm}^{3}$ of the obtained ABTS•+ solution was mixed with $60 \mathrm{~cm}^{3}$ of methanol. An amount of $1 \mathrm{~cm}^{3}$ of ABTS•+ solution and $1 \mathrm{~cm}^{3}$ of methanolic solution of tested compounds (prepared at different concentrations, as described before) was mixed and incubated for $7 \mathrm{~min}$ at $T=296.15 \mathrm{~K}$. The control contained methanol instead of the sample. The absorbance of the solutions was measured using UV-VIS spectrophotometer at $\lambda=734 \mathrm{~nm}$ against methanol (the reference). The ability to scavenge ABTS $\bullet+$ cation radicals was expressed as the percentage Inh ABTS $\bullet+$ and calculated according to the aforementioned Equation (6).

\subsubsection{FRAP Assay}

The FRAP assay was carried out in accordance with the procedure described in the reference [85]. The FRAP reagent was prepared by mixing $250 \mathrm{~cm}^{3}$ of acetate buffer 
( $c=300 \mathrm{mmol} \cdot \mathrm{dm}^{-3}$ at $\left.\mathrm{pH}=3.6\right), 25 \mathrm{~cm}^{3}$ of TPZT in $40 \mathrm{mmol} \cdot \mathrm{dm}^{-3} \mathrm{HCl}\left(c=10 \mathrm{mmol} \cdot \mathrm{dm}^{-3}\right)$ and $25 \mathrm{~cm}^{3}$ of $\mathrm{FeCl}_{3}$ aqueous solution $\left(c=20 \mathrm{mmol} \cdot \mathrm{dm}^{-3}\right)(10: 1: 1 \mathrm{v} / \mathrm{v} / \mathrm{v})$. Then, $3 \mathrm{~cm}^{3}$ of the freshly prepared FRAP reagent was added to $0.4 \mathrm{~cm}^{3}$ of methanolic solution of tested compounds and mixed thoroughly. After $8 \mathrm{~min}$ of incubation at $T=296.15 \mathrm{~K}$, the absorbance at $\lambda=595 \mathrm{~nm}$ was measured against a reference (containing $0.4 \mathrm{~cm}^{3}$ of methanol instead of the sample). Ferric reducing-antioxidant activity was expressed as $\mathrm{Fe}(\mathrm{II})$ ion equivalents $\left(\mu \mathrm{mol} \cdot \mathrm{dm}^{-3}\right)$ using the calibration curve obtained over the range of 0.050 $0.500 \mathrm{mmol} \cdot \mathrm{dm}^{-3}$ of $\mathrm{FeSO}_{4}$ (calibration curve regression: $\mathrm{y}=(3.4 \pm 0.2) \mathrm{x}-0.11 \pm 0.02$; $\left.R^{2}=0.9984\right)$.

\subsubsection{CUPRAC Assay}

The CUPRAC assay was conducted according to reference [86]. An amount of $250 \mathrm{~cm}^{3}$ of $\mathrm{CuCl}_{2}$ ( $c=10 \mathrm{mmol} \cdot \mathrm{dm}^{-3}$ in water) was mixed with $250 \mathrm{~cm}^{3}$ of ammonium acetate ( $\mathrm{pH}=7 \mathrm{in}$ water) and neocuproine $\left(c=75 \mathrm{mmol} \cdot \mathrm{dm}^{-3}\right.$ in methanol). Then, $3 \mathrm{~cm}^{3}$ of the CUPRAC mixture was added to $0.5 \mathrm{~cm}^{3}$ of methanolic solution of tested compound and $0.6 \mathrm{~cm}^{3}$ of distilled water. The samples were incubated for $60 \mathrm{~min}$ at room temperature $(T=296.15 \mathrm{~K})$. The absorbance of the samples was measured at $\lambda=450 \mathrm{~nm}$ against a reference (containing $0.5 \mathrm{~cm}^{3}$ of methanol instead of the sample). Cupric reducing antioxidant activity was expressed as Trolox equivalents $\left(\mu \mathrm{mol} \cdot \mathrm{dm}^{-3}\right)$ by using the calibration curve prepared over the range of $0.010-0.200 \mathrm{mmol} \cdot \mathrm{dm}^{-3}$ of Trolox $(\mathrm{y}=(4575.8 \pm 0.2) \mathrm{x}+0.027$ $\left.\pm 0.009 ; R^{2}=0.9919\right)$.

\subsubsection{Inhibition of the Lipid Peroxidation}

The inhibition of the lipid peroxidation of the compounds under study was estimated by the use of the ferric thiocyanate method as described in reference [87]. The percentage inhibition of lipid peroxidation (\% Inh) was also calculated according to the formula used during the DPPH assay (Equation (6)).

\section{Conclusions}

The europium sequestering ability of caffeic acid, an important natural derivative of abundant hydroxycinnamic acids, has been investigated in aqueous solutions and in solid state, in order to obtain some insights on the coordination mode of CFA towards $\mathrm{Eu}(\mathrm{III})$. It was observed that, while in aqueous solution, only 1:1 species are formed ([Eu(CFA)] and $\left.[\mathrm{Eu}(\mathrm{CFA})(\mathrm{OH})]^{-}\right)$, the solid formed within the synthetic procedure, was a 1:3 type of complex, with the proposed molecular formula of $\left[\mathrm{Eu}(\mathrm{CFA})_{3}\left(\mathrm{H}_{2} \mathrm{O}\right)_{3}\right] \cdot 2 \mathrm{H}_{2} \mathrm{O}$. Interestingly, in the $\mathrm{Eu}(\mathrm{III})$-caffeinate complex, we observed a destabilization of the aromatic ligand system under the influence of metal. This effect is the opposite when compared with the coordination of $\mathrm{Eu}(\mathrm{III})$ by cinnamic or $p$-coumaric acid, where $\mathrm{Eu}(\mathrm{III})$ has a stabilizing effect on the aromatic system. This is probably due to the observed different mode of coordination of the metal cation that, in the case of CFA, occurs via catecholate moiety, while cinnamic and $p$-coumaric acid complex the metal via the carboxylate group.

$\mathrm{Eu}(\mathrm{III})$ complexation by CFA affects the biological properties of the ligand, including antioxidant and antimicrobial activity. Eu(III)/CFA complex showed higher antimicrobial activity toward selected $\operatorname{Gram}(+)$ and $\operatorname{Gram}(-)$ bacteria when compared to the ligand alone. Based on the findings of other authors [27], this can be explained by an increase in the lipophilicity of Eu(III) complex that may result in a higher interaction with the cell membrane, leading to the change in cell permeability and/or damage to the membrane integrity. This effect was observed to be $\mathrm{pH}$ dependent; this is in agreement with the sequestering ability of the ligand that increases with an increase in $\mathrm{pH}$, resulting in the formation of a significant amount of Eu complexes. At higher $\mathrm{pH}$ values, the complexation of $\mathrm{Eu}(\mathrm{III})$ is more effective, so the changes of the membrane charge are more significant than in the case of free ligand. The lipophilicity does not seem to be an important parameter affecting the antioxidant properties of this complex in the conducted assays. The ability to donate a hydrogen or an electron to radical molecules is a crucial factor that determines 
whether a given chemical is a good or weak antioxidant. In the case of $\mathrm{Eu}(\mathrm{III}) / \mathrm{CFA}$, the hydroxyl groups of the catechol moiety are engaged in metal-ion coordination, which diminishes the hydrogen/electron donating properties of the complex compared to the ligand, as was shown on the basis of chemical tests. These considerations are proved by the lower antioxidant activity of Eu(III)/CFA than CFA.

The experiments conducted in more realistic conditions (corresponding to living organisms), e.g., on cell lines, could give different conclusions about the antioxidant activity of studied compounds, due to the possibility of easier penetration of the complex through the cell membrane and the interaction with the cell oxidative system. Such studies will be undertaken in further research.

Finally, all of these conclusions could only have been achieved through multi-analyticaltechnique approaches, since single experiments could not give a comprehensive picture of the chemical and biological behaviour of the various investigated systems.

Supplementary Materials: The following are available online at https:/ /www.mdpi.com/article/ 10.3390/ijms23020888/s1.

Author Contributions: Conceptualization, S.G., M.K. and B.G.-Ż.; Data curation, Ż.A., M.K., G.Ś., R.Ś., M.N., M.W., C.D.S. and D.M.; Funding acquisition, W.L. and B.G.-Ż.; Investigation, Ż.A., M.K., G.Ś., E.G., M.N., M.W., A.C. and A.P.; Methodology, S.G., C.D.S. and D.M.; Project administration, W.L. and B.G.-Ż.; Resources, W.L. and B.G.-Ż.; Software, S.G., C.D.S. and D.M.; Supervision, S.G., W.L. and B.G.-Ż.; Validation, S.G., C.D.S. and D.M.; Visualization, S.G., D.M. and B.G.-Ż.; Writing-original draft, Ż.A., M.K., G.Ś. and E.G.; Writing—review \& editing, S.G., R.Ś., M.N., A.C., A.P., D.M., W.L. and B.G.-Ż. All authors have read and agreed to the published version of the manuscript.

Funding: This research was funded by the National Science Centre (NCN), Poland, under the research project number 2018/29/B/NZ9/01997. This publication is also based upon work from COST Action CA18202-NECTAR—Network for Equilibria and Chemical Thermodynamics Advanced Research, supported by COST (European Cooperation in Science and Technology).

Acknowledgments: The authors thank Marta Hryniewicka for her help on the acquisition of the ESI-MS spectra.

Conflicts of Interest: The authors declare no conflict of interest.

\section{References}

1. Godlewska-Żyłkiewicz, B.; Świsłocka, R.; Kalinowska, M.; Golonko, A.; Świderski, G.; Arciszewska, Ż.; Nalewajko-Sieliwoniuk, E.; Naumowicz, M.; Lewandowski, W. Biologically Active Compounds of Plants: Structure-Related Antioxidant, Microbiological and Cytotoxic Activity of Selected Carboxylic Acids. Materials 2020, 13, 4454. [CrossRef] [PubMed]

2. Fu, J.; Cheng, K.; Zhang, Z.-M.; Fang, R.-Q.; Zhu, H.-L. Synthesis, structure and structure-activity relationship analysis of caffeic acid amides as potential antimicrobials. Eur. J. Med. Chem. 2010, 45, 2638-2643. [CrossRef] [PubMed]

3. Georgiev, L.; Chochkova, M.; Totseva, I.; Seizova, K.; Marinova, E.; Ivanova, G.; Ninova, M.; Najdenski, H.; Milkova, T. Anti-tyrosinase, antioxidant and antimicrobial activities of hydroxycinnamoylamides. Med. Chem. Res. 2013, 22, $4173-4182$. [CrossRef]

4. $\quad$ Lima, V.N.; Oliveira-Tintino, C.D.; Santos, E.S.; Morais, L.P.; Tintino, S.R.; Freitas, T.S.; Geraldo, Y.S.; Pereira, R.L.; Cruz, R.P.; Menezes, I.R.; et al. Antimicrobial and enhancement of the antibiotic activity by phenolic compounds: Gallic acid, caffeic acid and pyrogallol. Microb. Pathog. 2016, 99, 56-61. [CrossRef] [PubMed]

5. Kyselka, J.; Rabiej, D.; Dragoun, M.; Kreps, F.; Burčová, Z.; Němečková, I.; Smolová, J.; Bjelková, M.; Szydłowska-Czerniak, A.; Schmidt, Š.; et al. Antioxidant and antimicrobial activity of linseed lignans and phenolic acids. Eur. Food Res.Tech. 2017, 243, 1633-1644. [CrossRef]

6. Kępa, M.; Miklasińska-Majdanik, M.; Wojtyczka, R.D.; Idzik, D.; Korzeniowski, K.; Smoleń-Dzirba, J.; Wąsik, T.J. Antimicrobial Potential of Caffeic Acid against Staphylococcus aureus: Clinical Strains. BioMed Res. Int. 2018, 2018, 7413504. [CrossRef] [PubMed]

7. Khan, F.; Bamunuarachchi, N.I.; Tabassum, N.; Kim, Y.-M. Caffeic Acid and Its Derivatives: Antimicrobial Drugs toward Microbial Pathogens. J. Agric. Food Chem. 2021, 69, 2979-3004. [CrossRef]

8. Damasceno, S.; Dantas, B.; Ribeiro-Filho, J.; Antônio, M.; Galberto, M. Chemical Properties of Caffeic and Ferulic Acids in Biological System: Implications in Cancer Therapy. A Review. Curr. Pharm. Des. 2017, 23, 3015-3023. [CrossRef]

9. Świsłocka, R. Spectroscopic (FT-IR, FT-Raman, UV absorption, ${ }^{1} \mathrm{H}$ and ${ }^{13} \mathrm{C}$ NMR) and theoretical (in B3LYP/6-311++G ${ }^{* *}$ level) studies on alkali metal salts of caffeic acid. Spectrochim. Acta A Mol. Biomol. Spectrosc. 2013, 100, 21-30. [CrossRef] 
10. Matejczyk, M.; Świsłocka, R.; Golonko, A.; Lewandowski, W.; Hawrylik, E. Cytotoxic, genotoxic and antimicrobial activity of caffeic and rosmarinic acids and their lithium, sodium and potassium salts as potential anticancer compounds. Adv. Med. Sci. 2018, 63, 14-21. [CrossRef]

11. Cornard, J.P.; Lapouge, C. Theoretical and Spectroscopic Investigations of a Complex of Al(III) with Caffeic Acid. J. Phys. Chem. A 2004, 108, 4470-4478. [CrossRef]

12. Cornard, J.-P.; Caudron, A.; Merlin, J.-C. UV-visible and synchronous fluorescence spectroscopic investigations of the complexation of $\mathrm{Al}(\mathrm{III})$ with caffeic acid, in aqueous low acidic medium. Polyhedron 2006, 25, 2215-2222. [CrossRef]

13. Thoma, V.; Tampouris, K.; Petrou, A.L. Kinetics and mechanism of the reaction between chromium(III) and 3,4-dihydroxy-phenylpropenoic acid (caffeic acid) in weak acidic aqueous solutions. Bioinorg. Chem. Appl. 2008, 2008, 624583. [CrossRef]

14. Boilet, L.; Cornard, J.P.; Lapouge, C. Determination of the Chelating Site Preferentially Involved in the Complex of Lead(II) with Caffeic Acid: A Spectroscopic and Structural Study. J. Phys. Chem. A 2005, 109, 1952-1960. [CrossRef] [PubMed]

15. De Stefano, C.; Foti, C.; Giuffrè, O.; Sammartano, S. Acid-base and UV behavior of 3-(3,4-dihydroxyphenyl)-propenoic acid (caffeic acid) and complexing ability towards different divalent metal cations in aqueous solution. J. Mol. Liq. 2014, 195, 9-16. [CrossRef]

16. Živanović, S.C.; Veselinović, A.M.; Mitić, Ž.J.; Nikolić, G.M. The study of the influence of $\mathrm{Mg}(\mathrm{II})$ and Ca(II) ions on caffeic acid autoxidation in weakly alkaline aqueous solution using MCR-ALS analysis of spectrophotometric data. New J. Chem. 2018, 42, 6256-6263. [CrossRef]

17. Liddle, S.T.; Mills, D.P.; Natrajan, L.S. The Lanthanides and Actinides; World Scientific Publishing Europe Ltd.: London, UK, 2021.

18. Crea, F.; De Stefano, C.; Milea, D.; Sammartano, S. Thermodynamic data for lanthanoid(III) sequestration by phytate at different temperatures. Monatsh. Chem. 2010, 141, 511-520. [CrossRef]

19. Cigala, R.M.; De Stefano, C.; Irto, A.; Milea, D.; Sammartano, S. Thermodynamic Data for the Modeling of Lanthanoid(III) Sequestration by Reduced Glutathione in Aqueous Solution. J. Chem. Eng. Data 2015, 60, 192-201. [CrossRef]

20. Cotruvo, J.A., Jr. The Chemistry of Lanthanides in Biology: Recent Discoveries, Emerging Principles, and Technological Applications. ACS Cent. Sci. 2019, 5, 1496-1506. [CrossRef] [PubMed]

21. Kostova, I.; Traykova, M. Cerium(III) and neodymium(III) complexes as scavengers of X/XO-derived superoxide radical. Med. Chem. 2006, 2, 463-470. [CrossRef] [PubMed]

22. Kostova, I.; Peica, N.; Kiefer, W. Theoretical and spectroscopic studies of 5-aminoorotic acid and its new lanthanide(III) complexes. J. Raman Spectrosc. 2007, 38, 205-216. [CrossRef]

23. Kostova, I.; Momekov, G. New cerium(III) complexes of coumarins-Synthesis, characterization and cytotoxicity evaluation. Eur. J. Med. Chem. 2008, 43, 178-188. [CrossRef]

24. Kostova, I.; Valcheva-Traykova, M. New samarium(III) complex of 5-aminoorotic acid with antioxidant activity. Appl. Organometal. Chem. 2015, 29, 815-824. [CrossRef]

25. Ajlouni, A.M.; Abu-Salem, Q.; Taha, Z.A.; Hijazi, A.K.; Al Momani, W. Synthesis, characterization, biological activities and luminescent properties of lanthanide complexes with [2-thiophenecarboxylic acid, 2-(2-pyridinylmethylene)hydrazide] Schiff bases ligand. J. Rare Earths 2016, 34, 986-993. [CrossRef]

26. Kaczmarek, M.T.; Zabiszak, M.; Nowak, M.; Jastrzab, R. Lanthanides: Schiff base complexes, applications in cancer diagnosis, therapy, and antibacterial activity. Coord. Chem. Rev. 2018, 370, 42-54. [CrossRef]

27. Cota, I.; Marturano, V.; Tylkowski, B. Ln complexes as double faced agents: Study of antibacterial and antifungal activity. Coord. Chem. Rev. 2019, 396, 49-71. [CrossRef]

28. Kostova, I. Lanthanides as anticancer agents. Curr. Med. Chem. Anticancer Agents 2005, 5, 591-602. [CrossRef]

29. Boldyrev, I.A.; Gaenko, G.P.; Moiseeva, E.V.; Deligeorgiev, T.; Kaloyanova, S.; Lesev, N.; Vasilev, A.; Molotkovsky, J.G. Europium complexes of 1,10-phenanthrolines: Their inclusion in liposomes and cytotoxicity. Russ. J. Bioorg. Chem. 2011, 37, 364-368. [CrossRef]

30. Trusova, V.; Yudintsev, A.; Limanskaya, L.; Gorbenko, G.; Deligeorgiev, T. Europium coordination complexes as potential anticancer drugs: Their partitioning and permeation into lipid bilayers as revealed by pyrene fluorescence quenching. J. Fluoresc. 2013, 23, 193-202. [CrossRef] [PubMed]

31. Jabłońska-Trypuć, A.; Wydro, U.; Wołejko, E.; Świderski, G.; Lewandowski, W. Biological Activity of New Cichoric Acid-Metal Complexes in Bacterial Strains, Yeast-Like Fungi, and Human Cell Cultures In Vitro. Nutrients 2020, 12, 154. [CrossRef]

32. Kalinowska, M.; Sienkiewicz-Gromiuk, J.; Świderski, G.; Pietryczuk, A.; Cudowski, A.; Lewandowski, W. Zn(II) Complex of Plant Phenolic Chlorogenic Acid: Antioxidant, Antimicrobial and Structural Studies. Materials 2020, 13, 3745. [CrossRef] [PubMed]

33. Lewandowski, W.; Lewandowska, H.; Golonko, A.; Świderski, G.; Świsłocka, R.; Kalinowska, M. Correlations between molecular structure and biological activity in "logical series" of dietary chromone derivatives. PLoS ONE 2020, 15, e0229477. [CrossRef] [PubMed]

34. Kalinowska, M.; Gołębiewska, E.; Mazur, L.; Lewandowska, H.; Pruszyński, M.; Świderski, G.; Wyrwas, M.; Pawluczuk, N.; Lewandowski, W. Crystal Structure, Spectroscopic Characterization, Antioxidant and Cytotoxic Activity of $\mathrm{New} \mathrm{Mg}(\mathrm{II})$ and $\mathrm{Mn}(\mathrm{II}) / \mathrm{Na}$ (I) Complexes of Isoferulic Acid. Materials 2021, 14, 3236. [CrossRef]

35. Arena, K.; Brancato, G.; Cacciola, F.; Crea, F.; Cataldo, S.; De Stefano, C.; Gama, S.; Lando, G.; Milea, D.; Mondello, L.; et al. 8Hydroxyquinoline-2-Carboxylic Acid as Possible Molybdophore: A Multi-Technique Approach to Define Its Chemical Speciation, Coordination and Sequestering Ability in Aqueous Solution. Biomolecules 2020, 10, 930. [CrossRef] 
36. Cigala, R.M.; Cordaro, M.; Crea, F.; De Stefano, C.; Fracassetti, V.; Marchesi, M.; Milea, D.; Sammartano, S. Acid-Base Properties and Alkali and Alkaline Earth Metal Complex Formation in Aqueous Solution of Diethylenetriamine- $N, N, N^{\prime}, N^{\prime \prime}, N^{\prime \prime}-$ pentakis(methylenephosphonic acid) Obtained by an Efficient Synthetic Procedure. Ind. Eng. Chem. Res. 2014, 53, 9544-9553. [CrossRef]

37. Palma, E.; Mendes, F.; Morais, G.R.; Rodrigues, I.; Santos, I.C.; Campello, M.P.C.; Raposinho, P.; Correia, I.; Gama, S.; Belo, D.; et al. Biophysical characterization and antineoplastic activity of new bis(thiosemicarbazonato) $\mathrm{Cu}$ (II) complexes. J. Inorg. Biochem. 2017, 167, 68-79. [CrossRef] [PubMed]

38. Gabano, E.; Gama, S.; Mendes, F.; Gariboldi, M.B.; Monti, E.; Bombard, S.; Bianco, S.; Ravera, M. Study of the synthesis, antiproliferative properties, and interaction with DNA and polynucleotides of cisplatin-like Pt(II) complexes containing carcinogenic polyaromatic amines. J. Biol. Inorg. Chem. 2013, 18, 791-801. [CrossRef]

39. Kalinowska, M.; Piekut, J.; Bruss, A.; Follet, C.; Sienkiewicz-Gromiuk, J.; Świsłocka, R.; Rzączyńska, Z.; Lewandowski, W. Spectroscopic (FT-IR, FT-Raman, ${ }^{1} \mathrm{H},{ }^{13} \mathrm{C}$ NMR, UV/VIS), thermogravimetric and antimicrobial studies of Ca(II), $\mathrm{Mn}(\mathrm{II}), \mathrm{Cu}(\mathrm{II})$, Zn(II) and Cd(II) complexes of ferulic acid. Spectrochim. Acta A Mol. Biomol. Spectrosc. 2014, 122, 631-638. [CrossRef] [PubMed]

40. Świderski, G.; Łyszczek, R.; Wojtulewski, S.; Kalinowska, M.; Świsłocka, R.; Lewandowski, W. Comparison of structural, spectroscopic, theoretical and thermal properties of metal complexes ( $\mathrm{Zn}$ (II), Mn(II), Cu(II), Ni(II) and Co(II)) of pyridazine-3carboxylic acid and pyridazine-4-carboxylic acids. Inorg. Chim. Acta 2020, 512, 119865. [CrossRef]

41. Varsányi, G.; Kovner, M.A.; Láng, L. Assignments for Vibrational Spectra of 700 Benzene Derivatives; Akademiai Kiadó: Budapest, Hungary, 1973.

42. Lewandowski, W.; Fuks, L.; Kalinowska, M.; Koczon, P. The influence of selected metals on the electronic system of biologically important ligands. Spectrochim. Acta A Mol. Biomol. Spectrosc. 2003, 59, 3411-3420. [CrossRef]

43. Lewandowski, W.; Kalinowska, M.; Lewandowska, H. The influence of metals on the electronic system of biologically important ligands. Spectroscopic study of benzoates, salicylates, nicotinates and isoorotates. J. Inorg. Biochem. 2005, 99, 1407-1423. [CrossRef] [PubMed]

44. Nakamoto, K.; McCarthy, P.J. Spectroscopy and Structure of Metal Chelate Compounds; Wiley: New York, NY, USA, 1968.

45. Kalinowska, M.; Świsłocka, R.; Lewandowski, W. The spectroscopic (FT-IR, FT-Raman and ${ }^{1} \mathrm{H},{ }^{13} \mathrm{C}$ NMR) and theoretical studies of cinnamic acid and alkali metal cinnamates. J. Mol. Struct. 2007, 834, 572-580. [CrossRef]

46. Swislocka, R.; Kowczyk-Sadowy, M.; Kalinowska, M.; Lewandowski, W. Spectroscopic (FT-IR, FT-Raman, ${ }^{1} \mathrm{H}$ and ${ }^{13} \mathrm{C}$ NMR) and theoretical studies of $p$-coumaric acid and alkali metal p-coumarates. J. Spectrosc. 2012, 27, 546146. [CrossRef]

47. Lin, X.; Ning, E.; Li, X.; Li, Q. Construction of mixed carboxylate and pyrogallate building units for luminescent metal-organic frameworks. Chin. Chem. Lett. 2020, 31, 813-817. [CrossRef]

48. Dan, M.; Cheetham, A.K.; Rao, C.N.R. Diverse Structures and Dimensionalities in Hybrid Frameworks of Strontium and Lanthanum with Isomeric Dihydroxybenzoates. Inorg. Chem. 2006, 45, 8227-8238. [CrossRef]

49. Bizri, Y.; Cromer, M.; Lamy, I.; Scharff, J.P. Complexation dans les systèmes organo-minéraux modèles (acide cafféique et tiron) et naturels (substances humiques). Analusis 1985, 13, 128-133.

50. Gans, P.; Sabatini, A.; Vacca, A. HypSpec. Available online: http://www.hyperquad.co.uk (accessed on 15 October 2021).

51. Frassineti, C.; Ghelli, S.; Gans, P.; Sabatini, A.; Moruzzi, M.S.; Vacca, A. Nuclear Magnetic Resonance as a Tool for Determining Protonation Constants of Natural Polyprotic Bases in Solution. Anal. Biochem. 1995, 231, 374-382. [CrossRef]

52. Crea, F.; Milea, D.; Sammartano, S. Enhancement of hydrolysis through the formation of mixed hetero-metal species. Talanta 2005, 65, 229-238. [CrossRef]

53. Crea, F.; Milea, D.; Sammartano, S. Enhancement of Hydrolysis through the Formation of Mixed Hetero-Metal Species: Dioxouranium(VI)-Cadmium(II) Mixtures. Ann. Chim. 2005, 95, 767-778. [CrossRef] [PubMed]

54. Ekberg, C.; Brown, P.L. Hydrolysis of Metal Ions; Wiley-VCH, Verlag GmbH \& Co. KGaA: Weinheim, Germany, 2016.

55. Klungness, G.D.; Byrne, R.H. Comparative hydrolysis behavior of the rare earths and yttrium: The influence of temperature and ionic strength. Polyhedron 2000, 19, 99-107. [CrossRef]

56. Kiss, T.; Nagy, G.; Pécsi, M.; Kozlowski, H.; Micera, G.; Erre, L.S. Complexes of 3,4-dihydroxyphenyl derivatives-X. Copper(II) complexes of chlorogenic acid and related compounds. Polyhedron 1989, 8, 2345-2349. [CrossRef]

57. Sahoo, S.; Bera, R.K.; Baral, M.; Kanungo, B.K.A.C.S. Spectroscopic and Potentiometric Study of 2,3-Dihydroxybenzoic Acid and its Complexation with La(III) Ion. Acta Chim. Slov. 2008, 55, 243-247.

58. Cocks, S.; Under, P.W.; Voyé, A. Potentiometric Investigations of Equilibria Between Caffeic Acid and Manganese(II), Cobalt(II), Nickel(II) and Cadmium(II) Ions in Aqueous Solution. J. Coord. Chem. 1992, 25, 211-220. [CrossRef]

59. Adams, M.L.; O'Sullivan, B.; Downard, A.J.; Powell, K.J. Stability Constants for Aluminum(III) Complexes with the 1,2Dihydroxyaryl Ligands Caffeic Acid, Chlorogenic Acid, DHB, and DASA in Aqueous Solution. J. Chem. Eng. Data 2002, 47, 289-296. [CrossRef]

60. Beneduci, A.; Furia, E.; Russo, N.; Marino, T. Complexation behaviour of caffeic, ferulic and p-coumaric acids towards aluminium cations: A combined experimental and theoretical approach. New J. Chem. 2017, 41, 5182-5190. [CrossRef]

61. Malacaria, L.; Corrente, G.A.; Beneduci, A.; Furia, E.; Marino, T.; Mazzone, G. A Review on Coordination Properties of Al(III) and Fe(III) toward Natural Antioxidant Molecules: Experimental and Theoretical Insights. Molecules 2021, 26, 2603. [CrossRef]

62. Zhu, D.-H.; Kappel, M.J.; Raymond, K.N. Coordination chemistry of lanthanide catecholates. Inorg. Chim. Acta 1988, 147, 115-121. [CrossRef] 
63. Taha, M.; Khan, I.; Coutinho, J.A. Complexation and molecular modeling studies of europium(III)-gallic acid-amino acid complexes. J. Inorg. Biochem. 2016, 157, 25-33. [CrossRef]

64. Gama, S.; Frontauria, M.; Ueberschaar, N.; Brancato, G.; Milea, D.; Sammartano, S.; Plass, W. Thermodynamic study on 8hydroxyquinoline-2-carboxylic acid as a chelating agent for iron found in the gut of Noctuid larvae. New J. Chem. 2018, 42, 8062-8073. [CrossRef]

65. Gama, S.; Hermenau, R.; Frontauria, M.; Milea, D.; Sammartano, S.; Hertweck, C.; Plass, W. Iron Coordination Properties of Gramibactin as Model for the New Class of Diazeniumdiolate Based Siderophores. Chem. Eur. J. 2021, 27, 2724-2733. [CrossRef]

66. Bazzicalupi, C.; Bianchi, A.; Giorgi, C.; Clares, M.P.; García-España, E. Addressing selectivity criteria in binding equilibria. Coord. Chem. Rev. 2012, 256, 13-27. [CrossRef]

67. Crea, F.; De Stefano, C.; Foti, C.; Milea, D.; Sammartano, S. Chelating agents for the sequestration of mercury(II) and monomethyl mercury(II). Curr. Med. Chem. 2014, 21, 3819-3836. [CrossRef]

68. Harris, W.R.; Carrano, C.J.; Cooper, S.R.; Sofen, S.R.; Avdeef, A.E.; McArdle, J.V.; Raymond, K.N. Coordination chemistry of microbial iron transport compounds. 19. Stability constants and electrochemical behavior of ferric enterobactin and model complexes. J. Am. Chem. Soc. 1979, 101, 6097-6104. [CrossRef]

69. Overton, E. Studien über d. Narkose Zugleich ein Beitrag zur Allgemeinen Pharmakologie; Gustav Fisher: Jena, Germany, $1901 ;$ p. 195.

70. Tweedy, B.G. Plant Extracts with Metal Ions as Potential Antimicrobial Agents. Phytopatology 1964, 55, $910-918$.

71. Zong, G.-C.; Huo, J.-X.; Ren, N.; Zhang, J.-J.; Qi, X.-X.; Gao, J.; Geng, L.-N.; Wang, S.-P.; Shi, S.-K. Preparation, characterization and properties of four new trivalent lanthanide complexes constructed using 2-bromine-5-methoxybenzoic acid and 1,10phenanthroline. Dalton Trans. 2015, 44, 14877-14886. [CrossRef]

72. Mohanan, K.; Devi, S.N. Synthesis, characterization, thermal stability, reactivity, and antimicrobial properties of some novel lanthanide(III) complexes of 2-(N-salicylideneamino)-3-carboxyethyl-4,5,6,7-tetrahydrobenzo[b]thiophene. Russ. J. Coord. Chem. 2006, 32, 600-609. [CrossRef]

73. Ivanova, E.; Mitik-Dineva, N.; Mocanasu, R.; Murphy, S.; Wang, J.; Riessen, G.v.; Crawford, R. Vibrio fischeri and Escherichia coli adhesion tendencies towards photolithographically modified nanosmooth poly (tert-butyl methacrylate) polymer surfaces. Nanotechnol. Sci. Appl. 2008, 1, 33-44. [CrossRef]

74. Schott, H.; Young, C.Y. Electrokinetic Studies of Bacteria III: Effect of Polyvalent Metal Ions on Electrophoretic Mobility and Growth of Streptococcus faecalis. J. Pharm. Sci. 1973, 62, 1797-1801. [CrossRef]

75. Collins, Y.E.; Stotzky, G. Heavy metals alter the electrokinetic properties of bacteria, yeasts, and clay minerals. Appl. Environ. Microbiol. 1992, 58, 1592-1600. [CrossRef] [PubMed]

76. Spiegel, M.; Kapusta, K.; Kołodziejczyk, W.; Saloni, J.; Żbikowska, B.; Hill, G.A.; Sroka, Z. Antioxidant Activity of Selected Phenolic Acids-Ferric Reducing Antioxidant Power Assay and QSAR Analysis of the Structural Features. Molecules 2020, $25,3088$. [CrossRef]

77. Chen, J.; Yang, J.; Ma, L.; Li, J.; Shahzad, N.; Kim, C.K. Structure-antioxidant activity relationship of methoxy, phenolic hydroxyl, and carboxylic acid groups of phenolic acids. Sci. Rep. 2020, 10, 2611. [CrossRef] [PubMed]

78. Santos-Sánchez, F.; Villanueva-Cañongo, C.; Hernández-Carlos, B. Antioxidant compounds and their antioxidant mechanism in antioxidants. In Antioxidants; Shalaby, E., Ed.; IntechOpen: London, UK, 2019; pp. 1-28.

79. Litwinienko, G.; Ingold, K.U. Abnormal solvent effects on hydrogen atom abstraction. 2. Resolution of the curcumin antioxidant controversy. The role of sequential proton loss electron transfer. J. Org. Chem. 2004, 69, 5888-5896. [CrossRef] [PubMed]

80. Krȩżel, A.; Bal, W. A formula for correlating pKa values determined in $\mathrm{D}_{2} \mathrm{O}$ and $\mathrm{H}_{2}$ O. J. Inorg. Biochem. 2004, 98, 161-166. [CrossRef] [PubMed]

81. De Stefano, C.; Sammartano, S.; Mineo, P.; Rigano, C. Computer tools for the speciation of natural fluids. In Marine Chemistry-An Environmental Analytical Chemistry Approach; Gianguzza, A., Pelizzetti, E., Sammartano, S., Eds.; Kluwer Academic Publishers: Amsterdam, The Netherlands, 1997; pp. 71-83.

82. Alderighi, L.; Gans, P.; Ienco, A.; Peters, D.; Sabatini, A.; Vacca, A. Hyperquad simulation and speciation (HySS): A utility program for the investigation of equilibria involving soluble and partially soluble species. Coord. Chem. Rev. 1999, 184, 311-318. [CrossRef]

83. Kruszewski, M.; Kusaczuk, M.; Kotyńska, J.; Gál, M.; Krętowski, R.; Cechowska-Pasko, M.; Naumowicz, M. The effect of quercetin on the electrical properties of model lipid membranes and human glioblastoma cells. Bioelectrochemistry 2018, 124, $133-141$. [CrossRef]

84. Re, R.; Pellegrini, N.; Proteggente, A.; Pannala, A.; Yang, M.; Rice-Evans, C. Antioxidant activity applying an improved ABTS radical cation decolorization assay. Free Radic. Biol. Med. 1999, 26, 1231-1237. [CrossRef]

85. Diplock, A.T.; Symons, M.C.R.; Rice-Evans, C.A. Techniques in Free Radical Research; Elsevier Science: Amsterdam, The Netherlands, 1991; Volume 22.

86. Apak, R.; Güçlü, K.; Özyürek, M.; Karademir, S.E. Novel Total Antioxidant Capacity Index for Dietary Polyphenols and Vitamins C and E, Using Their Cupric Ion Reducing Capability in the Presence of Neocuproine: CUPRAC Method. J. Agric. Food Chem. 2004, 52, 7970-7981. [CrossRef]

87. Kikuzaki, H.; Nakatani, N. Antioxidant Effects of Some Ginger Constituents. J. Food Sci. 1993, 58, 1407-1410. [CrossRef] 